\title{
Advances in the development of a virtual car driver
}

\author{
M. Thommyppillai and S. Evangelou, Electrical and Electronic Engineering \\ and Mechanical Engineering, Imperial College, London SW7 2AZ, UK \\ Email: mark.thommyppillai/s.evangelou@imperial.ac.uk
}

\author{
R. S. Sharp, Mechanical, Medical and Aerospace Engineering, \\ Faculty of Engineering and Physical Sciences, University of Surrey, GU2 7XH, UK \\ Email: robinsharp@waitrose.com
}

April 30, 2009

\begin{abstract}
Fundamental approaches to modelling the control of a car by a driver are reviewed briefly. The context of the work presented is explained. Then, previous research on the application of optimal linear preview control to aspects of driving road vehicles is extended. This prior research treated the tracking of a roadway by a vehicle and driver at constant forward speed and the tracking of a speed demand while running straight. The two previously separate problems are now combined, so that longitudinal and lateral path demands are considered in parallel. A new feature is that low-pass filters are included in the driver modelling, to represent driver bandwidth limitations. This feature enables the finding of the influence of the driver's control bandwidth on the optimal strategies and on the closed-loop system performance, by way of frequency-response calculations. A new optimal preview control toolbox is employed. Simulations of the virtual driver-controlled car are shown to demonstrate the closed-loop system following longitudinal and lateral position demands.
\end{abstract}

Keywords: Road vehicle, car, driver, preview, tracking control, optimal, simulation 


\section{Introduction}

The work described is part of a research programme to create a practical virtual racing driver. Practicality implies both fast computation and the ability to fully exploit the potential performance of a realistic contemporary high-level racing car. The part of the programme considered here involves the extension of previous separate works on longitudinal control $[27,29]$ and lateral control $[25,26,28,30,34]$ to combined longitudinal and lateral controls. Recent work on the computation of optimal linear $\mathcal{H}_{2}$ preview controls, including the writing of a MATLAB toolbox $[11,12]$ see http://code.google.com/p/preview-control-toolbox/, is also newly exploited.

It has become the conventional wisdom that effective driving involves using information from ahead of the vehicle for control purposes [10, 14, 17], so-called preview, model predictive or receding-horizon control $[4,5]$. At the level of common experience, one only has to imagine trying to drive in the dark with headlights which illuminate the road only to the side of one's vehicle, to appreciate the loss of facility implied by lack of preview information.

Although nonlinear model predictive control (NMPC) theory has been developed and used extensively $[4,5,20,21]$, general truths about optimal preview control come more readily from linear theory. Among these truths are that:

1. beyond a preview extent that is problem-dependent, the returns available from increasing the preview available diminish towards zero. Thus it is possible to approximate the controlled system quality obtainable with infinite preview to an arbitrarily small degree by using finite-horizon control;

2. tight controls can be designed by weighting tracking accuracy highly and control power only a little, and conversely. Optimal linear preview control is not one scheme but is one of a whole family of schemes, for a given problem;

3. tight control can be characterized as requiring relatively short previews and yielding relatively large control efforts and conversely;

4. optimal linear quadratic preview controls for time-invariant systems are of state-feedback form and can be found off-line. The state which is fed back is that of the plant augmented 
with a shift register or delay-line, thus involving the preview information;

5. near-perfect tracking occurs with optimal linear systems within a frequency range that extends as the control tightness increases.

The dynamics of a racing car can be described as follows. Primary interest from a control viewpoint is in the longitudinal and lateral dynamics. Longitudinal control is mainly exercised by throttle and brake controls, while lateral control comes from the steering system. It is conventional to think of the throttle displacement, the brake pedal pressure and the steering wheel displacement as being the significant control inputs. The longitudinal dynamics are simpler than the lateral dynamics $[25-30,34]$ but both must be considered together in treating the general manoeuvring problem. The dynamic characteristics of the race-car vary strongly with speed. Within an operating range around the straight-running state, a linear representation of a (good) car is expected to be accurate. As manoeuvring severity increases, tyre shear forces saturate in a smooth and progressive manner. Near to saturation, shear forces depend on the frictional coupling between the tyres and the ground and longitudinal and lateral forces are in competition for the available friction. Controls derived assuming linearity are expected to work well for gentle manoeuvring and not so well for limit operation. A racing driver can be expected to know the dynamics of his/her car perfectly. Optimality of controls is vital. Robustness is not so important.

Neglecting practical issues relating to computing time, standard NMPC theory would provide virtual racing driver designs straightforwardly [18]. Such theory involves the parametrization of the path ahead of the vehicle and of the control history within the preview/control horizon. Then, at each computational step, a high-dimension nonlinear optimization problem has to be solved on-line. Convergence to the global optimum is not guaranteed and results are largely hidden from view. From any solution obtained, only the first step is used for control. The process is slow and extravagant. Compromise between accuracy of solution and speed of computation is essential.

Methods for simplifying NMPC calculations include:

1. shortening the preview and control horizons. Such shortening reduces the dimension of the optimization problem and thereby speeds it up. However, using foreshortened 
previews may spoil the results, even yielding instability for the controlled system $[4,5]$. In the limit, single-point preview and a single control level may be employed but the results are likely to be poor [10];

2. linearising the plant model to ease the computation of controls [14];

3. using a simplified plant model for control-design purposes $[3,6-9]$. The simplified-plantmodel approach is especially attractive if an approximation to the plant having particular simplifying characteristics can be found. For example, a kinematic vehicle, with purerolling tyres, may allow its states and inputs to be deduced from a knowledge of its outputs and their derivatives, so-called differential flatness [6-9]. Basing the control system design on a very simplified plant appears to be risky. Nevertheless, many examples of successful (virtual) tracking events incorporating such simplifications can be found in the literature. It should be noted, however, that modest tracking capabilities are easy to realize, while racing-driver performance levels are very high and will not be achieved readily.

In the view of the authors, an optimal racing lap is one in which the driver always operates the car in the neighbourhood of a trim state. This suggests that a good way to obtain the desired balance between speed of computation and vehicle control capability is to employ offline-computed optimal linear controls, with adaptation to deal with the progressive and smooth saturating nonlinearity of the car. In this schema, the theoretical driver pulls from memory a control design that is appropriate to current operating conditions, which we imagine is exactly what real drivers do. Each control design is optimal for a trim, which is close in state-vector terms to the current state of the vehicle. However, adaptation of the controls to the operating circumstances is not discussed further in this paper. That topic is covered elsewhere [35, 36]. Here, previous work on small-perturbation dynamics is developed through a car model which incorporates both throttle and steering actuators, with saturating engine and tyre shear force capabilities, and a control objective that includes longitudinal and lateral path tracking quality, according to a time schedule, together with control power minimization. Trim states, about which small perturbations are considered, include both straight-running, involving left/right symmetry, and cornering conditions without symmetry.

Although high-performance is the main aim, we take the opportunity to include driver 
response delay in the model, by incorporating second order Butterworth low-pass filters within throttle and steering actuators. Performance degradation associated with driver shortcomings is of interest in the engineering of production cars $[14,17,37]$ and slowing of driver actions surely represents one such degradation. This inclusion affords a new opportunity to study the influence of driver delays on the optimal control laws and the closed-loop system performance.

In the next section, the car model is described. This is followed by a brief outline of the optimal preview control theory employed. Then, we describe the use of open-loop simulation runs to find trim or dynamic equilibrium states for the vehicle, both for straight-running where left/right symmetry exists and for cornering, where the symmetry is broken. Optimal controls for both classes of trim state are discussed and the influences of driver lags highlighted. Simulations of the closed-loop longitudinal and lateral path-tracking system are described and finally conclusions are drawn.

\section{Vehicle Model}

The car model is built using the multibody-modelling software VehicleSim®, formerly called AutoSim [15, 22, 33], also see http://www.carsim.com. The starting point for any VehicleSimbased model building is an inertial reference frame. The first added body is allowed to move with up to six degrees of freedom with respect to the inertial frame. Children bodies of this, or any other body present, can be added, with a description of the freedoms permitted to this new body, relative to its parent body. In the nominal configuration of the system, the point common to both parent body and child body, names for the mass and inertia elements etc. need to be defined. The symbolic equations of motion are derived via Kane's equations, which are based on the principle of virtual power [23]. Points can be defined in bodies. These are most often fixed points in the bodies to which they belong but they may be specified as "moving", with their locations specified by coordinates in a defined reference system. Forces with given magnitudes and directions can be applied to points and reacted to choice. Alternatively, a strut following a force law can be defined as acting between two points, in which case, the direction of the force is that of the line joining the points. Moments with magnitudes and directions can be defined as acting between bodies. 
New state variables can be added to a model and they can be made integral functions of existing variables. Differentials with respect to time and partial differentials of variables can be defined. Abs, ifthen, max, min and sign functions can be used, allowing discontinuous actions, like tyres leaving the ground and limit stops being contacted, to be modelled easily. The analyst can define how discontinuous functions are to be differentiated. Alternatively, the model can be made continuous for linearization purposes by restricting its range of operation.

Equations are prepared in the form:

$$
\begin{aligned}
& {[\mathrm{S}(\mathbf{q}, \mathbf{t})] \dot{\boldsymbol{q}}=\boldsymbol{\nu}(\boldsymbol{q}, \boldsymbol{u}, \boldsymbol{t}) \quad \text { kinematics }} \\
& {[\mathrm{M}(\mathbf{q}, \mathbf{t})] \dot{\boldsymbol{u}}=\boldsymbol{f}(\boldsymbol{q}, \boldsymbol{u}, \boldsymbol{t})}
\end{aligned}
$$

in which $\mathbf{S}$ and $\mathbf{M}$ are matrices, $\boldsymbol{\nu}$ is a vector function, $\boldsymbol{q}$ is the generalized displacement vector, $\boldsymbol{u}$ is the generalized speed vector and $\boldsymbol{f}$ is the force vector. Equation 1 defines the geometric relationships between the generalized coordinates and generalized speeds, while equation 2 defines the equations of motion. These equations, required parameter values and desired outputs can be written by VehicleSim into a simulation code, with the aid of a "C" or "FORTRAN" compiler, or they can be linearized for small perturbations about a general trim state and written into a MATLAB "M"-file. Typically, for linear analysis, the nonlinear simulation program is used to find trim states and the equilibrium values of states and inputs are passed to MATLAB to set up the numerical state-space form of the linear system equations.

The car model consists of the bodies and freedoms shown in Figure 1. The chassis has all six degrees of freedom. Each wheel is suspended by a transverse swing axle, having a pivot axis location which is quite general, allowing the representation of any desired small-perturbation lateral properties. Geometric parameters are chosen to position the suspension roll centres [2] at ground level in the nominal state. The longitudinal properties are simple. The suspension geometry is illustrated by Figure 2, while a side-view of the car is shown in Figure 3.

Each front wheel steers around a nominally vertical axis, with a small offset, the mechanical trail, forwards from the wheel centre. A simple steering system includes a steering wheel, whose displacement is given by the output of the relevant low-pass filter. The steering wheel displacement combines with the pinion rotation to determine the torque in the steering column, 


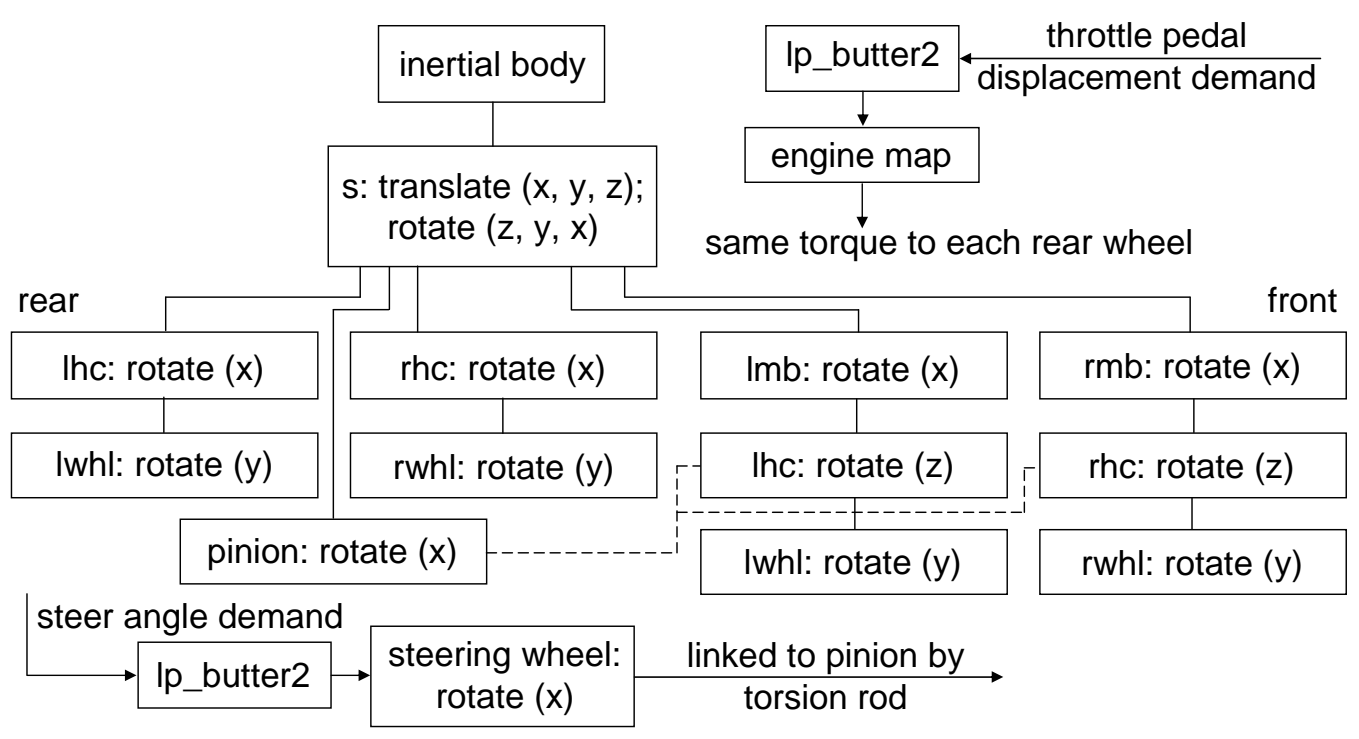

Figure 1: Bodies and freedoms included in car model. Low-pass filters associated with throttle and steering actuators, to represent driver response delays are also shown. mb means "massless body". hc means "hub carrier" and whl means "wheel". The steering wheel is linked to the pinion by a torsion rod, which, in turn, is linked to the front hub carriers by torsion springs through a gear ratio. 1 means "left" and $\mathrm{r}$ means "right".

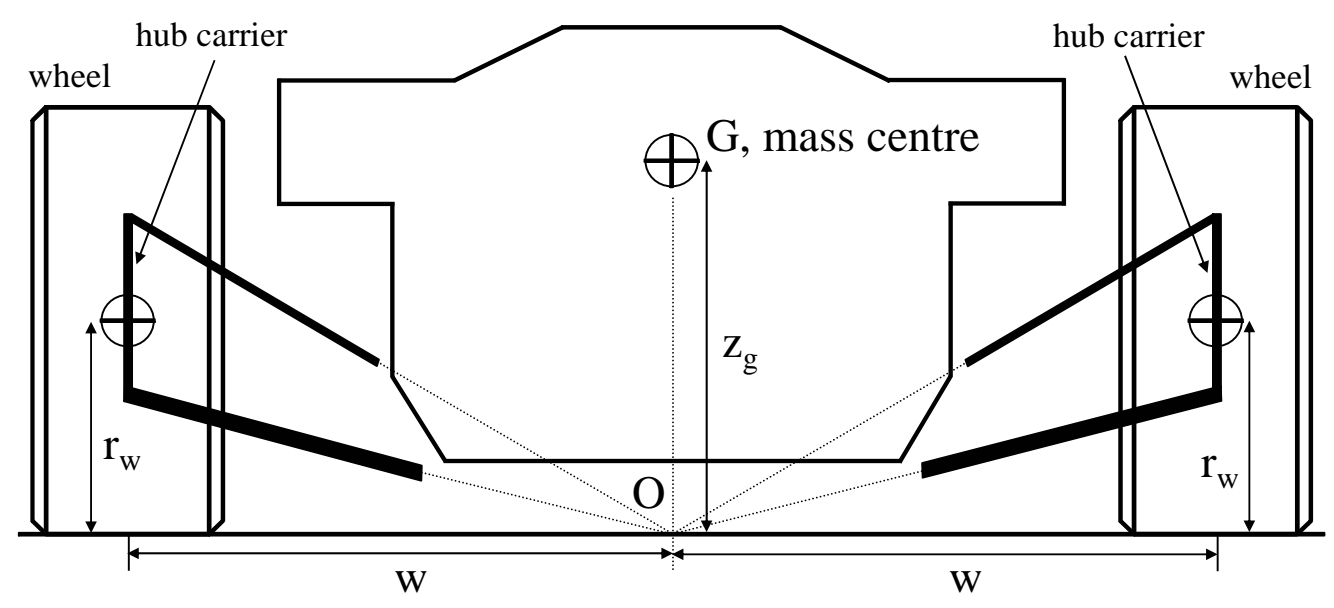

Figure 2: Diagrammatic view of car suspension from rear. The instantaneous centre of rotation of each wheel is at ground level on the car's centre-line. 


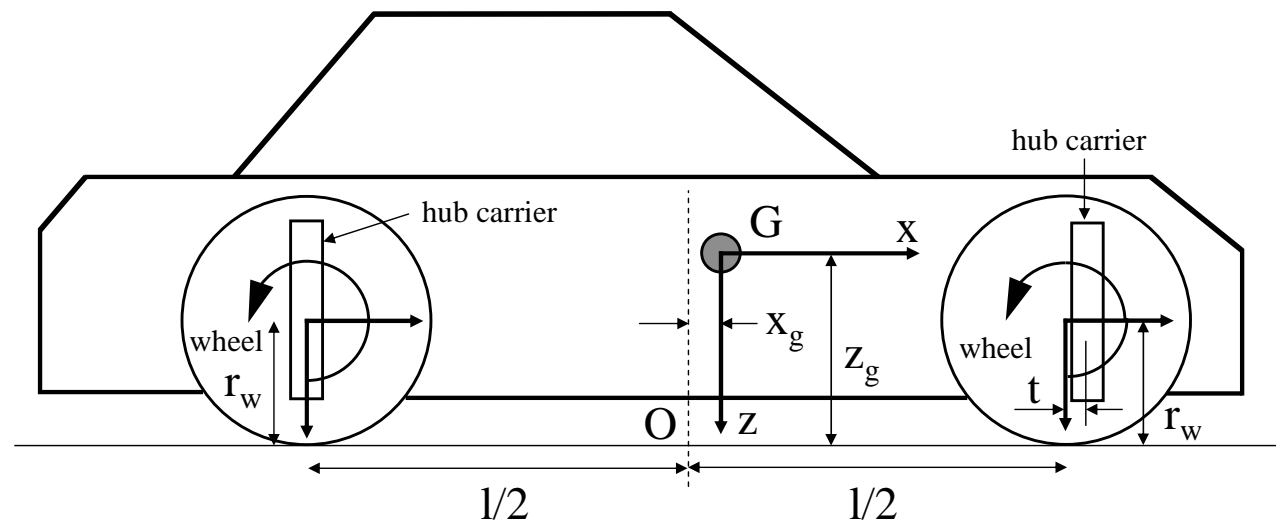

Figure 3: Diagrammatic view of car from right side.

with the pinion linking to each front hub carrier through a gear ratio and torsion rod.

The throttle pedal displacement is treated like the steering wheel angle, with the pedal displacement combining with the engine speed to yield an output torque, that is divided equally between the rear wheels. In the linear model, pedal displacement and steer angle demands are the inputs. Front and rear anti-roll bars are included and simple aerodynamic drag, $0.5 C_{d} \rho A V^{2}$, and lift forces, $0.5 C_{l f} \rho A V^{2}$ and $0.5 C_{l r} \rho A V^{2}$, act on the chassis. $C_{d}, C_{l f}$ and $C_{l r}$ are coefficients, $\rho$ is air density and $V$ is the car speed. Bump-steer is included at each wheel station, to the extent that suspension displacement influences the lateral slip ratio for the appropriate tyre, thereby affecting the tyre force system. Parameter values specifying the car and tyres in detail represent a typical contemporary European family saloon. Car parameters are given in Table 1.

Tyre shear forces and moments are represented by a combined-slip model that uses a combination of the well-known "Magic Formula" [16] and normalization [24, 31, 32]. The model deals realistically with completely general running conditions. Pure-slip longitudinal and lateral forces are illustrated in Figure 4.

The engine torque output, $\chi$, is described by throttle-opening and engine-speed functions of "Magic Formula" form:

$$
\begin{aligned}
\chi=\frac{D_{s}}{\omega} & \sin \left[\arctan \left(B_{t} d_{g}-E_{t}\left(B_{t} d_{g}-\arctan \left(B_{t} d_{g}\right)\right)\right)\right] . \\
& \sin \left[C_{s} \arctan \left(B_{s} \omega-E_{s}\left(B_{s} \omega-\arctan \left(B_{s} \omega\right)\right)\right)\right]
\end{aligned}
$$




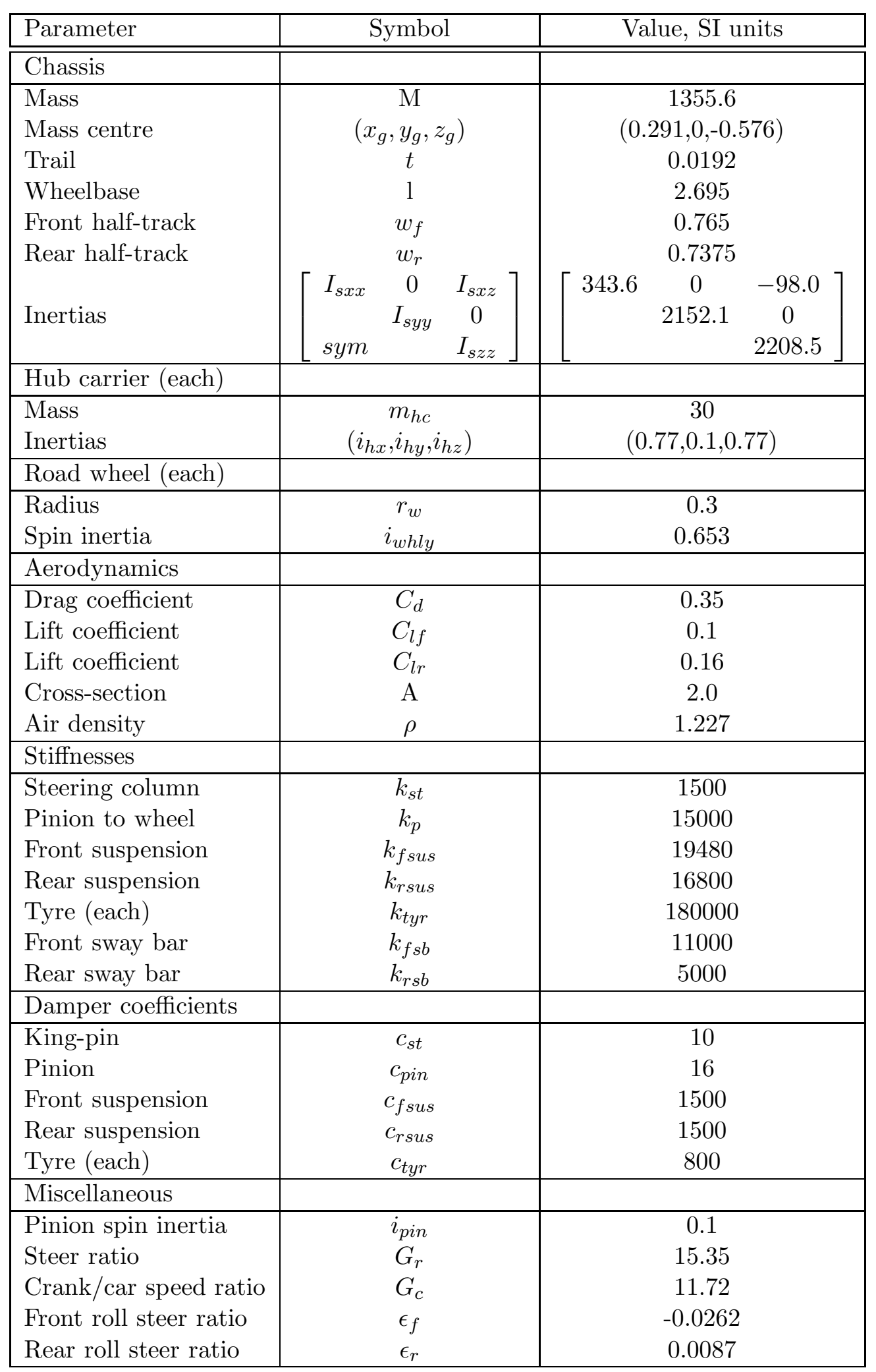

Table 1: Symbols and parameter values of the car. 

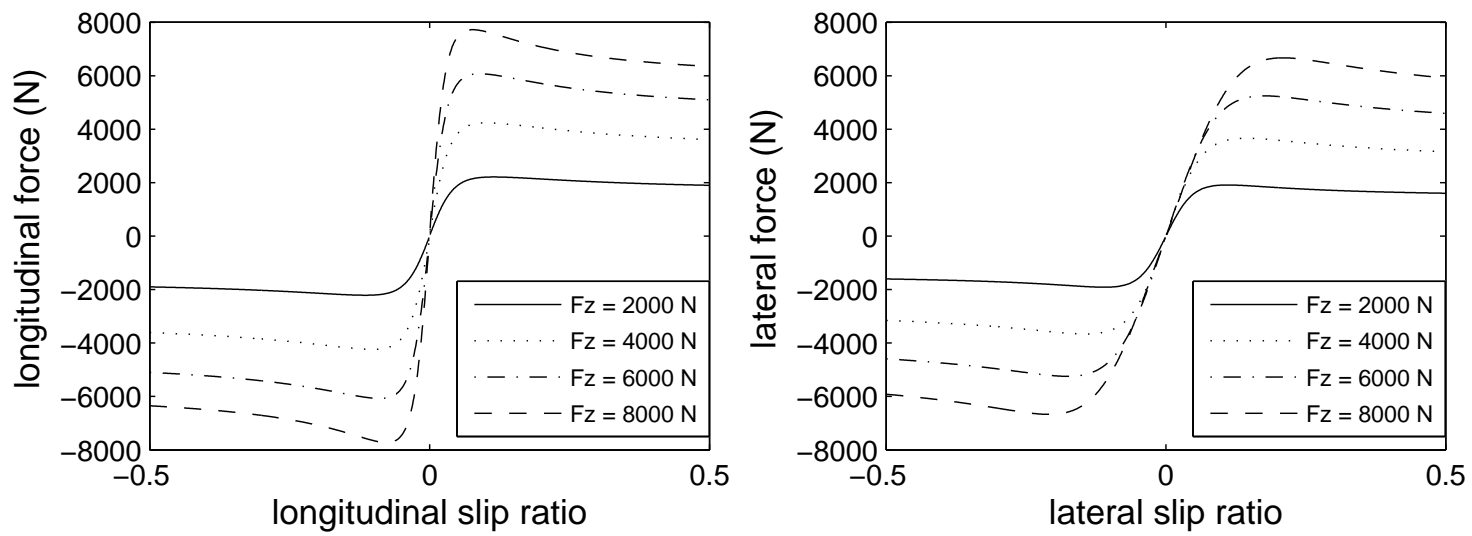

Figure 4: Longitudinal (left) and lateral (right) tyre forces associated with variations in load and longitudinal or lateral slip ratio respectively, for zero camber angle. Tyre parameters used come directly from [32].

in which $B_{s}, C_{s}, D_{s}$ and $E_{s}$ are engine-speed-shaping and $B_{t}$ and $E_{t}$ are throttle-openingshaping parameters, $d_{g}$ is the throttle opening ratio and $\omega$ is the engine speed in $\mathrm{rad} / \mathrm{s}$. Engine torque output is limited to positive values and is shown in Figure 5 as a function of speed and throttle opening. If the throttle opening becomes negative, proportional braking torques are applied to each road wheel in the ratio 70 percent front, 30 percent rear. Left and right wheels are treated equally with respect to braking.

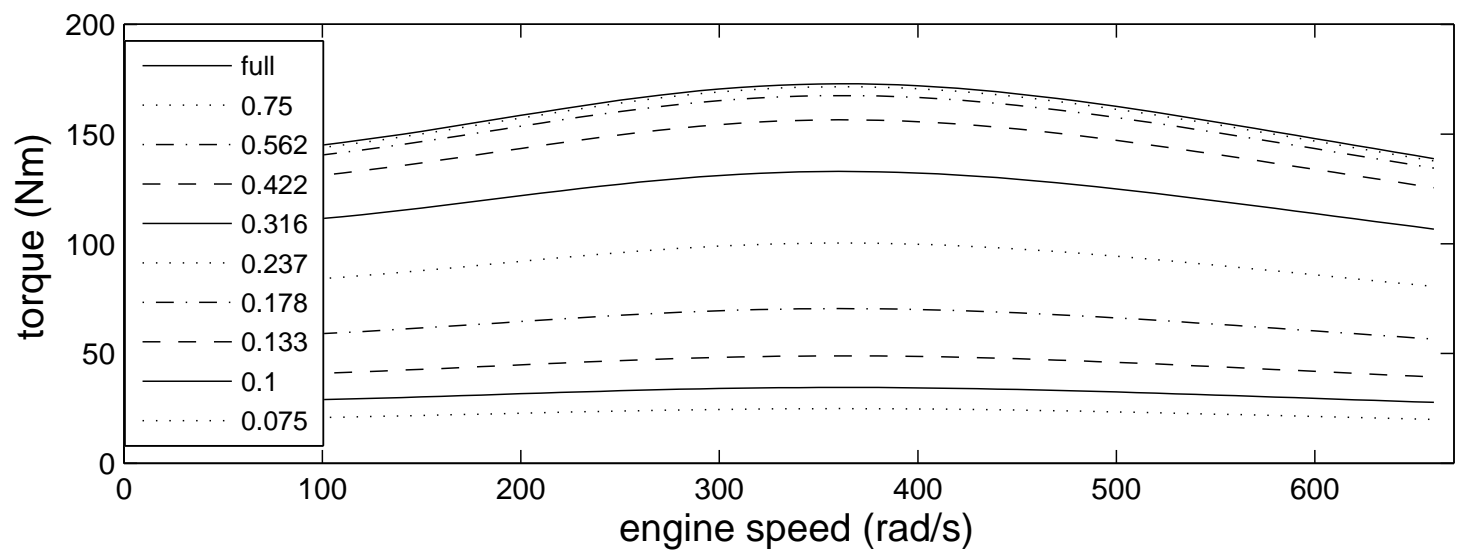

Figure 5: Engine torque output as a function of engine speed and throttle opening. Parameter values are $B_{s}=0.0014, C_{s}=1.6, D_{s}=100000, E_{s}=-8, B_{t}=1.8, E_{t}=-12$, see equation 3 . 


\section{Optimal Linear Preview Control Theory}

In studies of preview steering control already completed, a linear vehicle model is arranged to include the absolute lateral displacement of its reference point as a state and to have steering torque or steering displacement as a primary control input. The model is put into discretetime form, using a time step of $T$ say. Through each time step, the vehicle travels $V T$ where $V$ is the specified speed. A roadway lateral profile is defined by discrete points $V T$ apart longitudinally in the inertial reference system, so that all the road profile points in front of the vehicle approach it by $V T$ through each time step. In this inertial reference system, illustrated in Figure 6, the road dynamics are those of a shift register or delay line and the equations describing these dynamics are of the same form as the equations of the vehicle. The two sets of equations are combined to yield a composite system, with its state-vector having a partition for the vehicle and a partition for the road. At this first stage, there is no coupling between the parts.

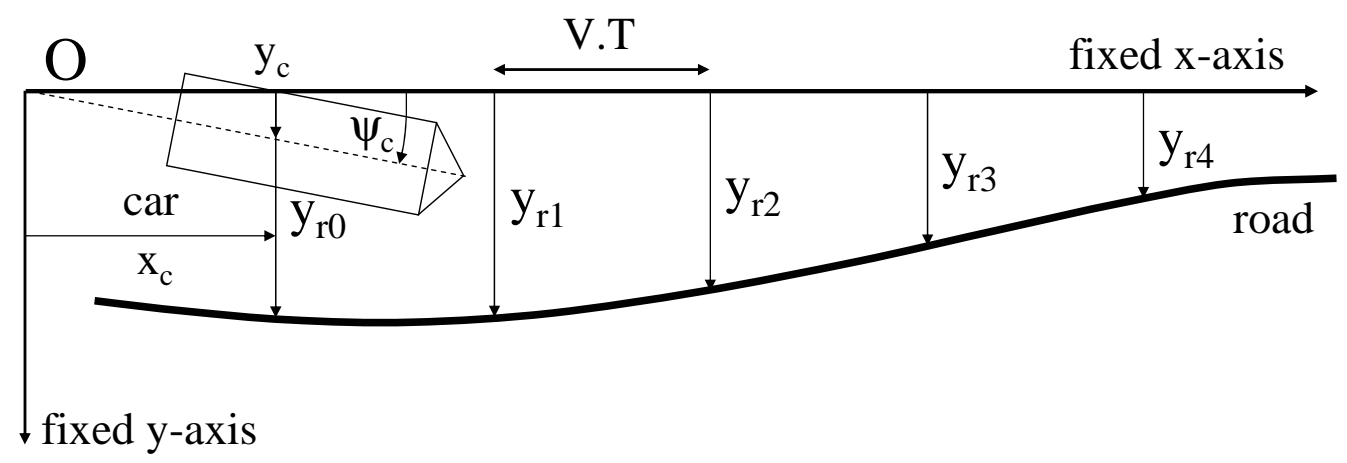

Figure 6: Diagrammatic representation of a car tracking a road at constant speed, with the whole system referenced to ground. Such a description implies that the road sample values pass through a serial-in, parallel-out shift register operation at each time step. The dynamics of the shift register are easy to specify mathematically. 
Suppose the discrete-time linearised vehicle equations are:

$$
\begin{gathered}
\boldsymbol{x}_{\boldsymbol{v}}(k+1)=\mathbf{A}_{\mathbf{v}} \boldsymbol{x}_{\boldsymbol{v}}(k)+\mathbf{B}_{\mathbf{v}} \boldsymbol{\tau}(k) \\
\boldsymbol{y}_{\boldsymbol{v}}(k)=\mathbf{C}_{\mathbf{v}} \boldsymbol{x}_{\boldsymbol{v}}(k)
\end{gathered}
$$

with discrete-time counter $\mathrm{k}$, vehicle state vector $\boldsymbol{x}_{\boldsymbol{v}}$ and control input $\boldsymbol{\tau}$, and let the road equation be:

$$
\boldsymbol{\eta}_{\boldsymbol{r}}(k+1)=\mathbf{A}_{\mathbf{r}} \boldsymbol{\eta}_{\boldsymbol{r}}(k)+\mathbf{B}_{\mathbf{r}} \boldsymbol{\eta}_{\boldsymbol{r} \boldsymbol{n}}(k)
$$

with $(2 \mathrm{n} \times 1)$ road state $\boldsymbol{\eta}_{\boldsymbol{r}}$ and road sample values that enter the system at time $k T$ being the $(2 \times 1) \boldsymbol{\eta}_{\boldsymbol{r} \boldsymbol{n}}, 2$ being the number of previewable disturbances and $\mathrm{n}$ being the number of preview steps included. In the present case, the input is:

$$
\boldsymbol{\tau}(k)=\left[\begin{array}{ll}
d_{g} & \theta_{s}
\end{array}\right]^{T}
$$

$d_{g}$ being throttle pedal displacement and $\theta_{s}$ being steering wheel angle. $\boldsymbol{\eta}_{\boldsymbol{r} \boldsymbol{n}}$ here represents both x-displacement and y-displacement demands.

To represent the road shift register process, $\mathbf{A}_{\mathbf{r}}$ is $(2 \mathrm{n} \times 2 \mathrm{n})$ and has the form:

$$
\mathbf{A}_{\mathbf{r}}=\left[\begin{array}{ccccc}
\mathbf{0}_{2} & \mathbf{I}_{2} & \mathbf{0}_{2} & \ldots & \mathbf{0}_{2} \\
\mathbf{0}_{2} & \mathbf{0}_{2} & \mathbf{I}_{2} & \ldots & \mathbf{0}_{2} \\
\vdots & \vdots & \vdots & \ddots & \vdots \\
\mathbf{0}_{2} & \mathbf{0}_{2} & \mathbf{0}_{2} & \ldots & \mathbf{I}_{2} \\
\mathbf{0}_{2} & \mathbf{0}_{2} & \mathbf{0}_{2} & \ldots & \mathbf{0}_{2}
\end{array}\right]
$$

and $\mathbf{B}_{\mathbf{r}}$, corresponding to the two previewable disturbances, is $(2 \mathrm{n} \times 2)$ and has the form:

$$
\mathbf{B}_{\mathbf{r}}=\left[\begin{array}{lllllllll}
0 & 0 & 0 & 0 & 0 & 0 & \ldots & 1 & 0 \\
0 & 0 & 0 & 0 & 0 & 0 & \ldots & 0 & 1
\end{array}\right]^{T}
$$

Here, $\mathbf{0}_{\mathbf{2}}$ is a $(2 \times 2)$ zero matrix while $\mathbf{I}_{\mathbf{2}}$ is a $(2 \times 2)$ identity matrix. 
Combining vehicle and road equations together, the full dynamic system is defined by:

$$
\left[\begin{array}{c}
\boldsymbol{x}_{\boldsymbol{v}}(k+1) \\
\boldsymbol{\eta}_{\boldsymbol{r}}(k+1)
\end{array}\right]=\left[\begin{array}{cc}
\mathbf{A}_{\mathbf{v}} & 0 \\
0 & \mathbf{A}_{\mathbf{r}}
\end{array}\right]\left[\begin{array}{c}
\boldsymbol{x}_{\boldsymbol{v}}(k) \\
\boldsymbol{\eta}_{\boldsymbol{r}}(k)
\end{array}\right]+\left[\begin{array}{c}
\mathbf{B}_{\mathbf{v}} \\
0
\end{array}\right] \boldsymbol{\tau}(k)+\left[\begin{array}{c}
0 \\
\mathbf{B}_{\mathbf{r}}
\end{array}\right] \boldsymbol{\eta}_{\boldsymbol{r n}}(k)
$$

which takes the standard discrete-time form:

$$
\begin{gathered}
\boldsymbol{z}(k+1)=\mathbf{A} z(k)+\mathbf{B} \boldsymbol{u}(k)+\mathbf{E} \boldsymbol{\eta}_{\boldsymbol{r n}}(k) \\
\boldsymbol{y}(k)=\mathbf{C} \boldsymbol{z}(k)
\end{gathered}
$$

If $\boldsymbol{\eta}_{\boldsymbol{r n}}$ contains samples from two uncorrelated white-noise random sequences, the timeinvariant optimal control which minimizes a quadratic cost function $J$, given that the pair $(\mathbf{A}, \mathbf{B})$ is stabilizable and that the pair $(\mathbf{A}, \mathbf{C})$ is detectable [1], is:

$$
\boldsymbol{u}^{*}(k)=\boldsymbol{K} \boldsymbol{z}(k)
$$

where $\boldsymbol{K}=-\left(\mathbf{R}+\mathbf{B}^{\mathbf{T}} \mathbf{P B}\right)^{-1} \mathbf{B}^{\mathbf{T}} \mathbf{P A}$, given that the cost function $J$ is:

$$
J=\lim _{n \rightarrow \infty} \sum_{k=0}^{n}\left\{\boldsymbol{z}^{\boldsymbol{T}}(k) \mathbf{Q} \boldsymbol{z}(k)+\boldsymbol{u}^{\boldsymbol{T}}(k) \mathbf{R} \boldsymbol{u}(k)\right\}
$$

and $\mathbf{P}$ satisfies the matrix-difference-Riccati equation:

$$
\mathbf{P}=\mathbf{A}^{\mathbf{T}} \mathbf{P A}-\mathbf{A}^{\mathbf{T}} \mathbf{P B}\left(\mathbf{R}+\mathbf{B}^{\mathbf{T}} \mathbf{P B}\right)^{-1} \mathbf{B}^{\mathbf{T}} \mathbf{P A}+\mathbf{Q}
$$

Here $\mathbf{Q}=\mathbf{C}^{\mathbf{T}} \mathbf{q} \mathbf{C}$ and $\mathbf{q}$ is a diagonal weighting matrix, $\operatorname{diag}\left[q_{1}, q_{2}, \ldots\right]$, with terms corresponding to the number of performance aspects contributing to the cost function, and $\mathbf{R}$ is a $(2 \times 2)$ diagonal weighting on the control inputs, throttle pedal displacement and steering wheel angle. $\mathbf{C}$ is chosen such that the quadratic term $\boldsymbol{z}^{\boldsymbol{T}}(k) \mathbf{Q} \boldsymbol{z}(k)$ in the cost function $J$ penalizes the sum of the squares of the differences between the $(\mathrm{x}, \mathrm{y})$ coordinates of the car's reference point and the corresponding $(\mathrm{x}, \mathrm{y})$ of the road, over the optimization horizon. Since there are only these two aspects of performance in the cost, $\mathbf{q}$ is $(2 \times 2)$. 
Calculation of the optimal controls is non-trivial $[11,12]$. In previous work involving only a single input signal, a method described in $[13,19,29,30,34]$ was employed but it is now preferred to use Hazell's MATLAB Toolbox. The Toolbox requires only the setting up of the standard state-space (A, B, C, D) matrices, the setting of weights on tracking errors and control efforts, and the calling of special functions, for the optimal controls to be revealed. The problem structure and optimal controls are illustrated in Figure 7 . The preview gains $\boldsymbol{K}_{\mathbf{2}}$ inevitably fall to zero as the preview distance increases, so that the number of preview points included can be chosen, by trials, so that effectively the full benefit available is obtained. This is referred to as "full" preview. Only full preview control is of interest in the present context.

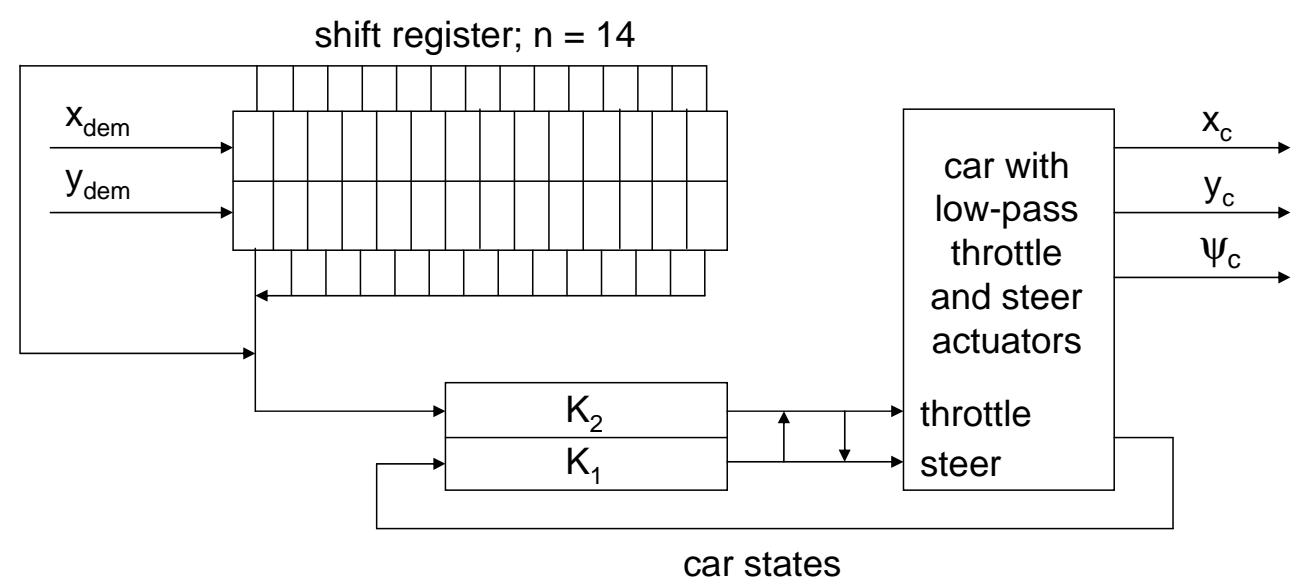

Figure 7: Structure of the two-control, $\mathrm{x}$ - and y-input preview tracking system. $x_{d e m}$ and $y_{\text {dem }}$ are the previewable longitudinal and lateral displacement signals. $\boldsymbol{K}_{\mathbf{1}}$ represents the full car-state feedback, while $\boldsymbol{K}_{\mathbf{2}}$ represents the preview control, in the form of feedback of the shift register states.

\section{Optimal Controls}

Examples of optimal controls are shown in this section. Each set of controls generated requires choices of:

1. the trim state from which small perturbations are considered to occur;

2. the time step to be used in the problem discretization;

3. $\mathrm{x}$ - and $\mathrm{y}$-tracking error weights; 
4. control power weights relating to throttle displacement demand and steering wheel angle demand;

5. the number of preview points to be used. In this work, the last is always chosen, by trials, to give full preview.

With the following somewhat arbitrary choices, sampling interval $=0.01 \mathrm{~s}$, straight-running at $35 \mathrm{~m} / \mathrm{s}$, x-weight and y-weight of 50 ; throttle displacement weighting 50 and steer angle weighting 1, the main feedback controls for driver filter bandwidths, $\omega_{n}$, of 3.15, 12.6 and $50.4 \mathrm{rad} / \mathrm{s}$ are shown in Figure 8. The left/right symmetry of the straight-running trim state is matched by symmetry in the feedback gains, shown in connection with variables 2 and 3 and with 4 and 5 in the lower part of the figure. The symmetry implies complete decoupling at first order of the longitudinal and lateral problems, so that x-errors lead to zero preview gains in respect of the steering system and y-errors lead to zero preview gains relating to the throttle control. Such preview gains are shown in Figure 9.

Feedback gains are influenced systematically but not dramatically by the control bandwidth. The gains are usually largest for the slowest-responding "driver". Preview controls change only a little with changes to the driver bandwidth when the driver dynamics are fast relative to those of the car. As the driver becomes slower than the car, the gain sequence is "stretched" longitudinally. More preview is utilized to compensate for the system delay, which result can be expected intuitively.

Results belonging to a cornering trim state are now generated. The trim state chosen is for a speed of $17.54 \mathrm{~m} / \mathrm{s}$, a lateral acceleration of $7.22 \mathrm{~m} / \mathrm{s}^{2}$ and a body roll angle of $-6.46^{\circ}$. Tyre loads, lateral forces, normalized slips, longitudinal slip ratios and lateral slip ratios for the trim state are shown in Table 2 . The tyre shear-force model has the potentially useful property that the normalized slip is directly related to the adhesion utilization, that is, the extent to which the tyre to road friction is being used. Peak shear force is obtained for the tyre-normalized-slip parameter $\lambda_{n}=2.325$ [32], so that the front right (inside) tyre, with normalized slip 5.644, is operating on the declining part of the shear-force curve. It is peripheral to the present purpose but the trim condition shows the case for anti-Ackermann steering geometry, which would allow the adhesion utilization of the two front tyres to be more nearly equal. 

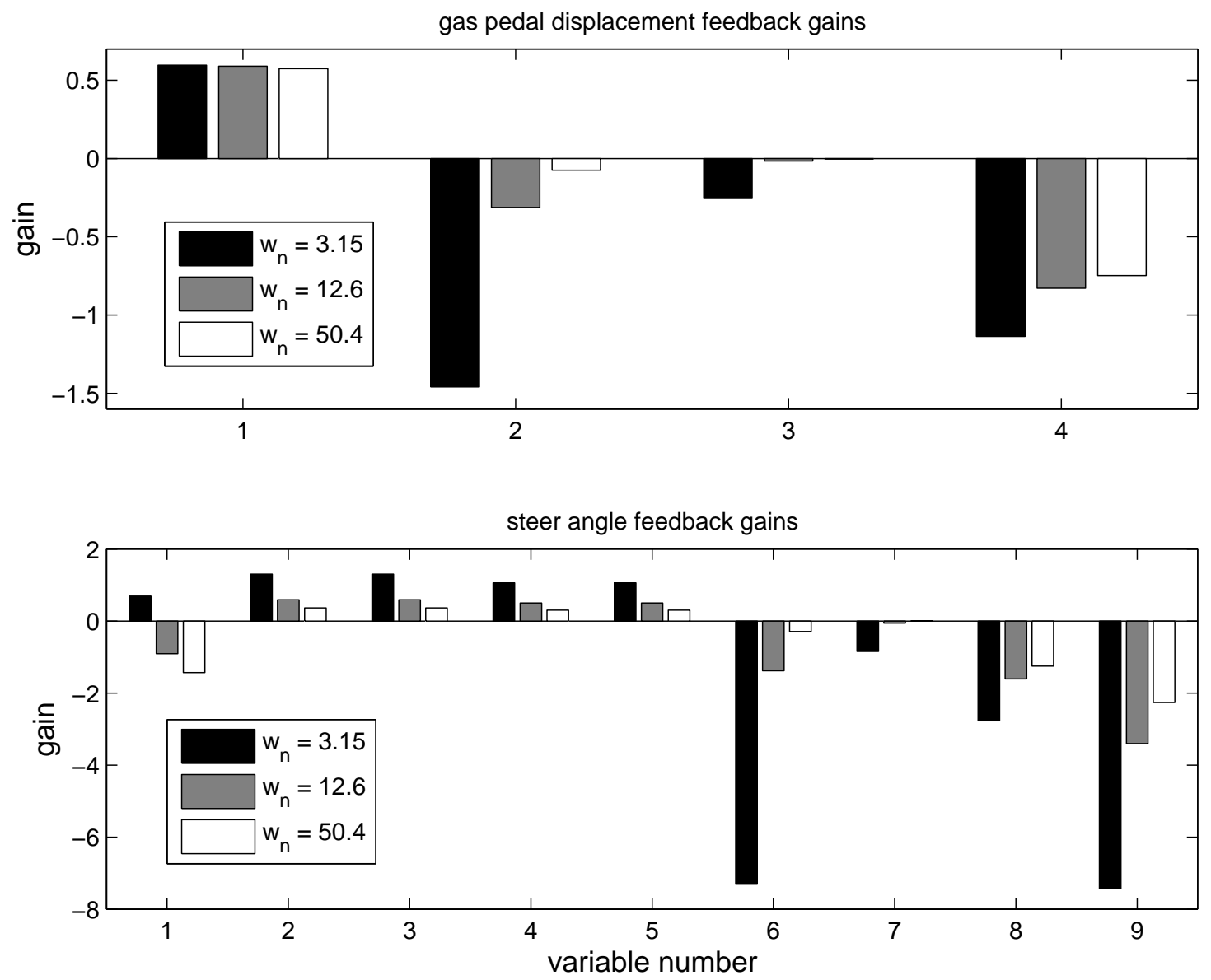

Figure 8: Main feedback control gains for a representative straight-running trim state at 35 $\mathrm{m} / \mathrm{s}$, with $\mathbf{Q}=\left[\begin{array}{llll}50 & 0 & 0 & 50\end{array}\right]$ and $\mathbf{R}=\left[\begin{array}{llll}50 & 0 ; & 0 & 1\end{array}\right]$ and three values for the driver filter cut-off frequency, $\omega_{n}$. Variables fed back to the throttle demand are: $1=$ body pitch angle, $2=$ throttle filter "position", $3=$ throttle filter "velocity", $4=$ vehicle speed. Variables fed back to the steering demand are: $1=$ body roll angle, $2=$ front right suspension deflection, $3=$ front left suspension deflection, $4=$ rear right suspension deflection, $5=$ rear left suspension deflection, $6=$ steer filter "position", $7=$ steer filter "velocity", $8=$ lateral velocity, 9=yaw velocity. 

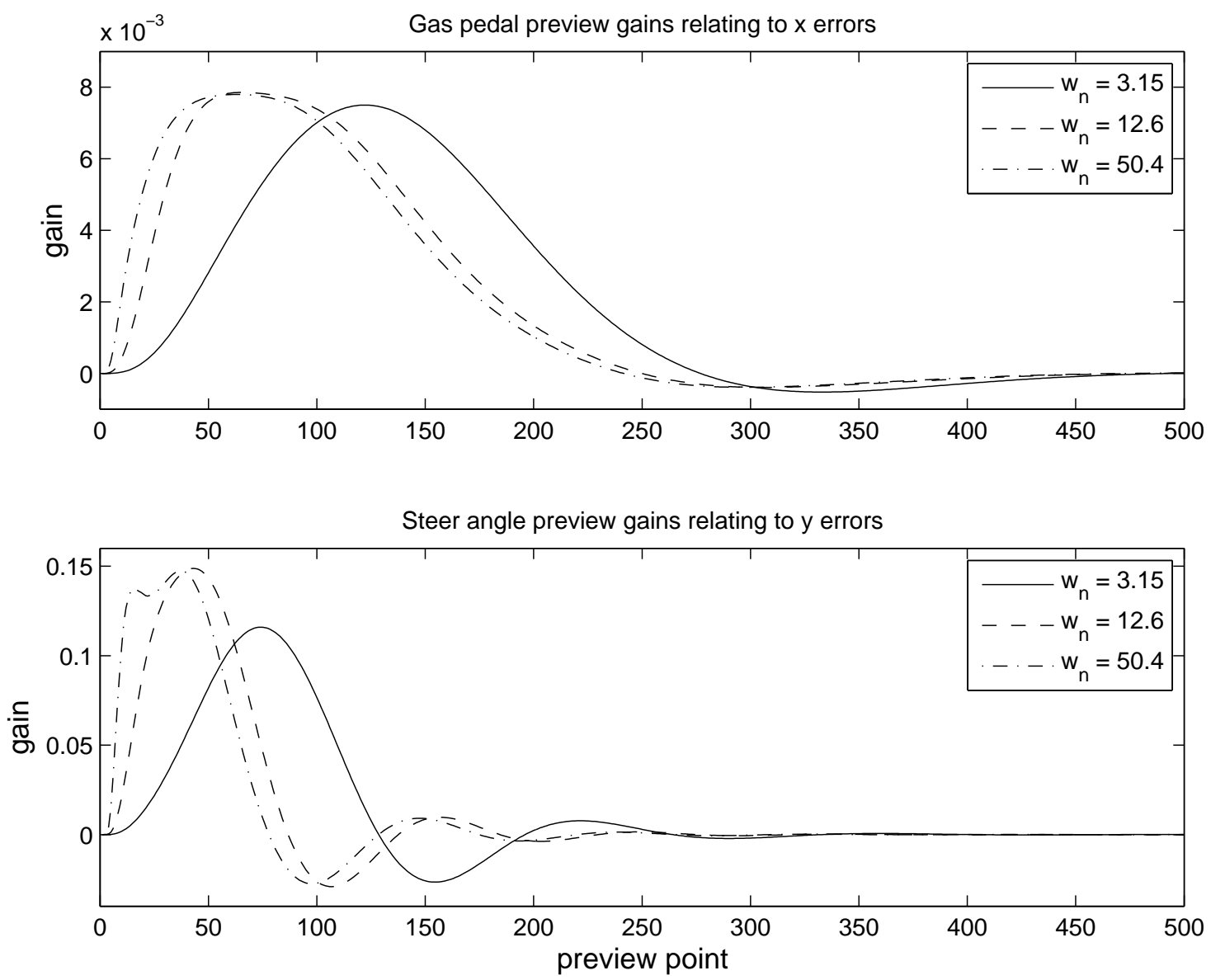

Figure 9: Preview gains for straight-running trim at $35 \mathrm{~m} / \mathrm{s}$, with $\mathbf{Q}=\left[\begin{array}{ll}50 & 0 ; 0\end{array} 0\right.$ 50] and $\mathbf{R}=$ $[500 ; 01]$ and three values for the driver filter cut-off frequency, $\omega_{n}$. Steering gains for x-errors and throttle gains for y-errors are zero by symmetry. These are omitted from the figures in the interests of clarity. 
The left/right symmetry has gone, so the longitudinal and lateral problems are cross-coupled and the optimal controls are more complex than before, see Figures 10 and 11. The control computations involve the same weightings as above, with $\omega_{n}=12.6 \mathrm{rad} / \mathrm{s}$. The high gain associated with pitch angle feedback to steer angle is surprising. Throttle displacements in response to lateral position errors are not much smaller than those deriving from longitudinal errors. The extent of the steer angle desired in response to a longitudinal position error is quite large for this particular trim state, involving high lateral acceleration.

\begin{tabular}{|l|c|c|c|c|c|}
\hline & tyre load & side-force & $\lambda_{n}$ & $\kappa$ & $\alpha$ \\
\hline \hline front right & $828 \mathrm{~N}$ & $731 \mathrm{~N}$ & 5.644 & 0 & 0.2220 \\
front left & $7531 \mathrm{~N}$ & $6268 \mathrm{~N}$ & 2.382 & 0 & 0.2141 \\
rear right & $1790 \mathrm{~N}$ & $1240 \mathrm{~N}$ & 1.340 & 0.0329 & 0.0505 \\
rear left & $4226 \mathrm{~N}$ & $2690 \mathrm{~N}$ & 0.8440 & 0.0096 & 0.0488 \\
\hline
\end{tabular}

Table 2: Tyre loads, tyre side-forces, normalized slips, long-slips and side-slips for cornering trim state at $17.54 \mathrm{~m} / \mathrm{s}$ speed and $7.22 \mathrm{~m} / \mathrm{s}^{2}$ lateral acceleration. $\lambda_{n}$ is normalized slip, $\kappa$ is longitudinal slip ratio, $\alpha$ is lateral slip ratio.

The tracking capabilities of the closed-loop system can be demonstrated by calculating frequency responses [27, 29, 30]. We imagine demanding a small-amplitude sinusoidal perturbation on the steady motion in longitudinal or lateral direction and calculate the sustained response of the driver-controlled system to such a demand. The frequency of the perturbation is varied over a range and the calculations repeated. Results are represented in Bode diagram form, showing gain and phase against circular frequency. The input to the closed-loop system is at the furthest extent, from the car, of the preview. That is, it is at the preview horizon. The car is required to track what the driver can see at the horizon. It will take some time for the car to arrive at the preview horizon, so that perfect tracking is indicated by a gain of unity and a phase lag corresponding to the transport delay. This phase lag amounts to $180 \mathrm{nT} \omega / \pi^{\circ}$, where $\mathrm{n}$ is the number of preview points, $\mathrm{T}$ the discrete time step and $\omega$ is the circular frequency of the perturbation. Results are shown firstly for perturbations from a straight-running trim state with speed of $35 \mathrm{~m} / \mathrm{s}$, driver filter bandwidths of $3.15,12.6$ and $50.4 \mathrm{rad} / \mathrm{s}, \mathbf{Q}=[500 ; 0$ 50] and $\mathbf{R}=\left[\begin{array}{llll}50 & 0 ; & 0 & 1\end{array}\right]$ and 500 preview points, Figures 12 and 13 . Figure 12 relates to the longitudinal response of the car to an x-displacement demand, while Figure 13 relates to the lateral response to a y-displacement demand. 

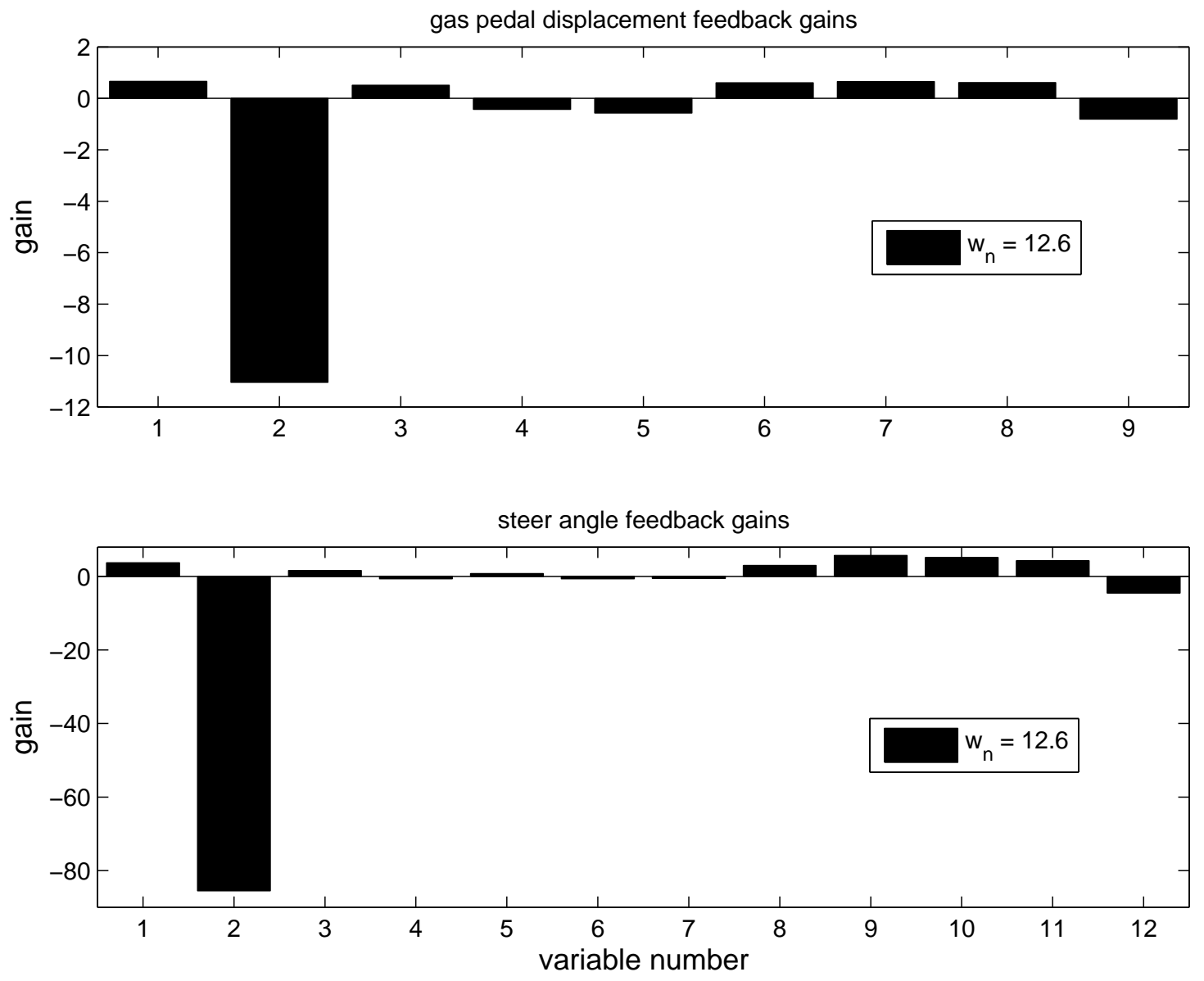

Figure 10: Main feedback control gains for a representative cornering trim state at 17.54 $\mathrm{m} / \mathrm{s}$ speed and $7.22 \mathrm{~m} / \mathrm{s}^{2}$ lateral acceleration, with $\mathbf{Q}=\left[\begin{array}{llll}50 & 0 ; & 0 & 50\end{array}\right]$ and $\mathbf{R}=\left[\begin{array}{llll}50 & 0 ; & 0 & 1\end{array}\right]$. Variables fed back to the throttle demand are: $1=$ body bounce displacement, $2=$ body pitch angle, $3=$ body roll angle, $4=$ throttle filter "position", $5=$ forward velocity, $6=$ lateral velocity, $7=$ bounce velocity, $8=$ yaw velocity, $9=$ pitch velocity. Variables fed back to the steering demand are: $1=$ body bounce displacement, $2=$ body pitch angle, $3=$ body roll angle, $4=$ front right suspension deflection, $5=$ front left suspension deflection, $6=$ rear right suspension deflection, $7=$ rear left suspension deflection, $8=$ forward velocity, $9=$ lateral velocity, $10=$ bounce velocity, $11=$ yaw velocity, $12=$ pitch velocity. 

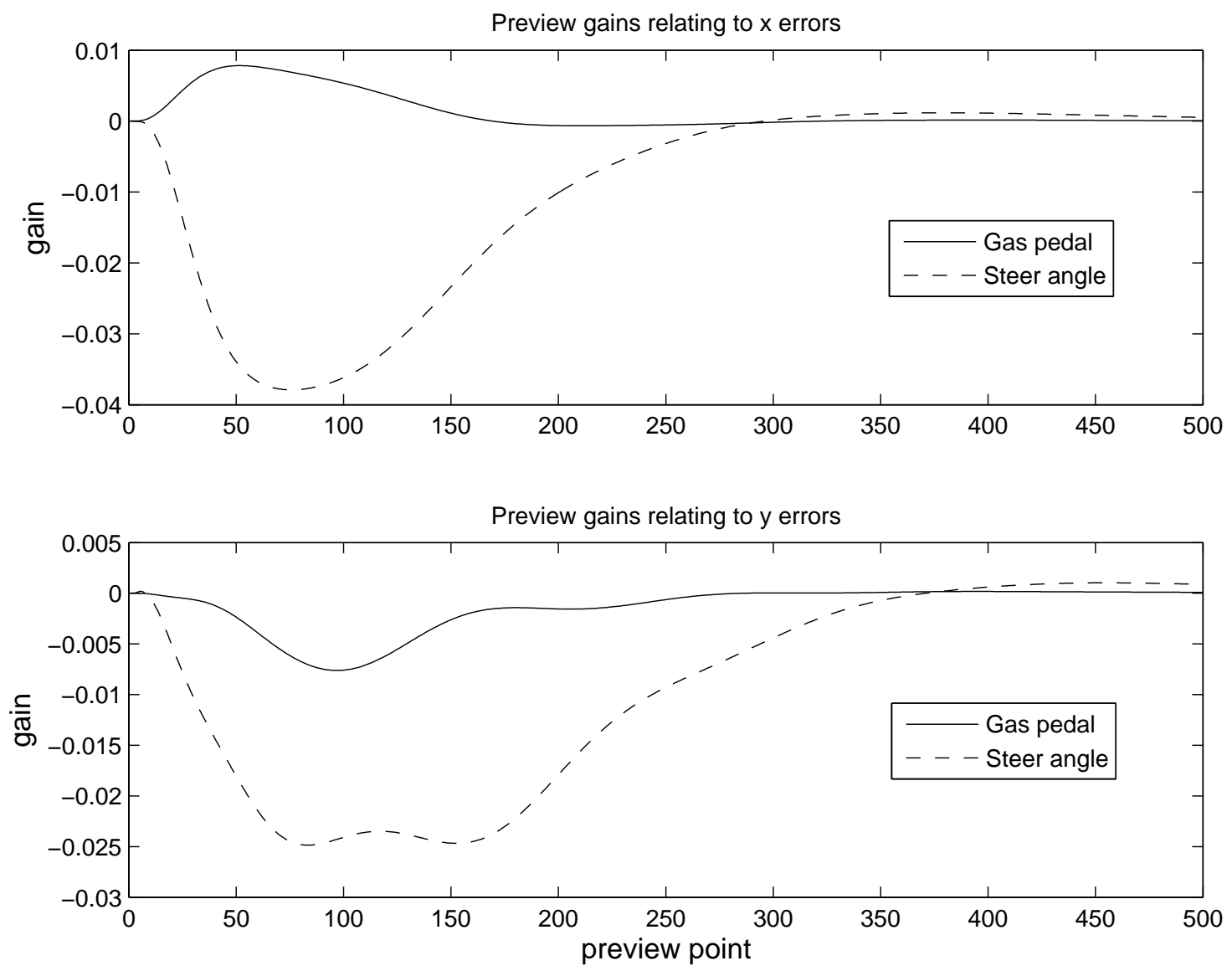

Figure 11: Preview gains for the cornering trim state at $17.44 \mathrm{~m} / \mathrm{s}$ and lateral acceleration of $7.32 \mathrm{~m} / s^{2}$, with $\mathbf{Q}=\left[\begin{array}{llll}50 & 0 & 0 & 50\end{array}\right]$ and $\mathbf{R}=\left[\begin{array}{llll}50 & 0 ; & 0 & 1\end{array}\right] . \omega_{n}=12.6 \mathrm{rad} / \mathrm{s}$. The tyre forces are near to saturation for this trim state. 

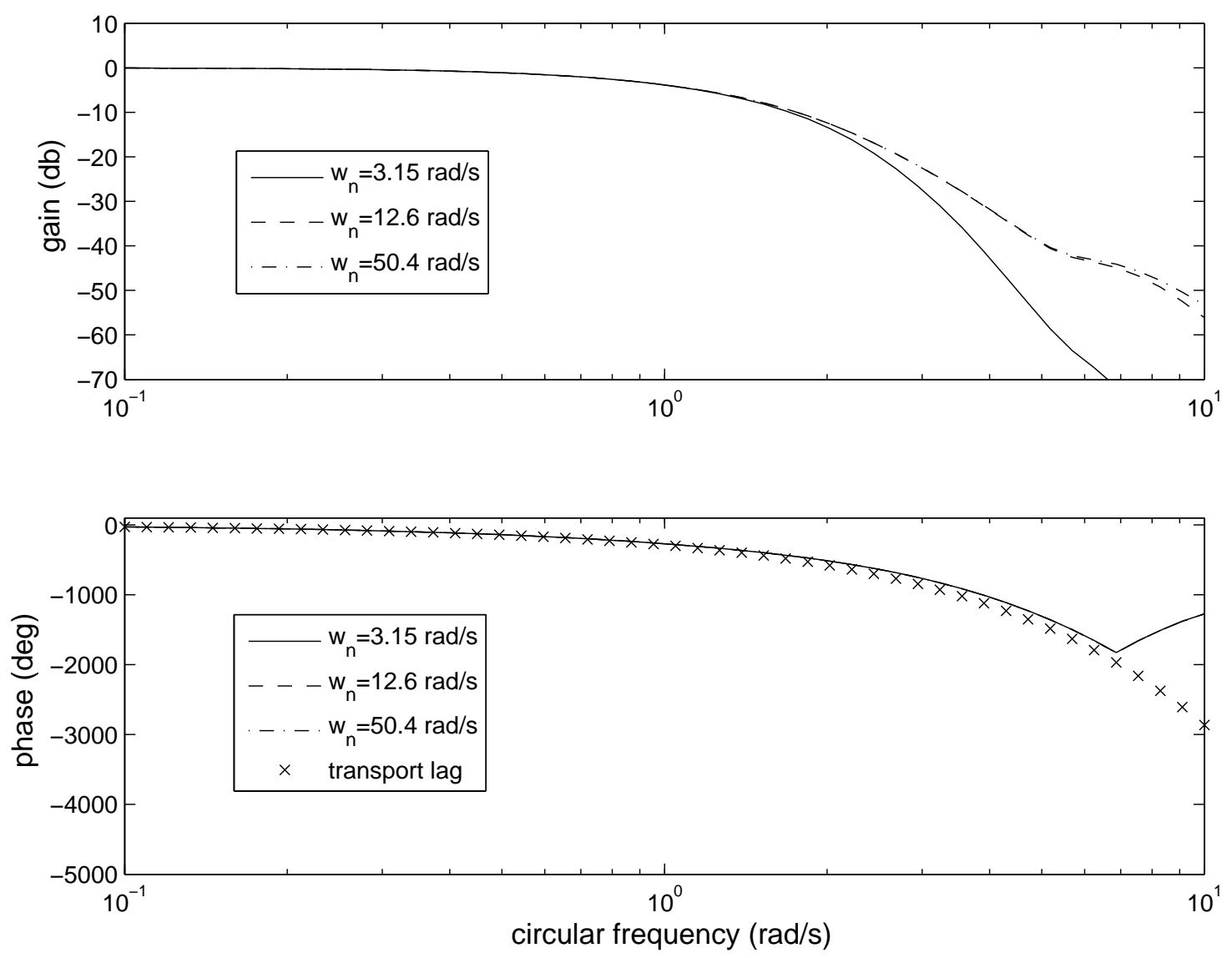

Figure 12: Longitudinal frequency responses for driver-controlled car linearized around a

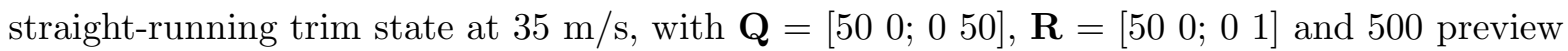
points, for three driver bandwidths. 

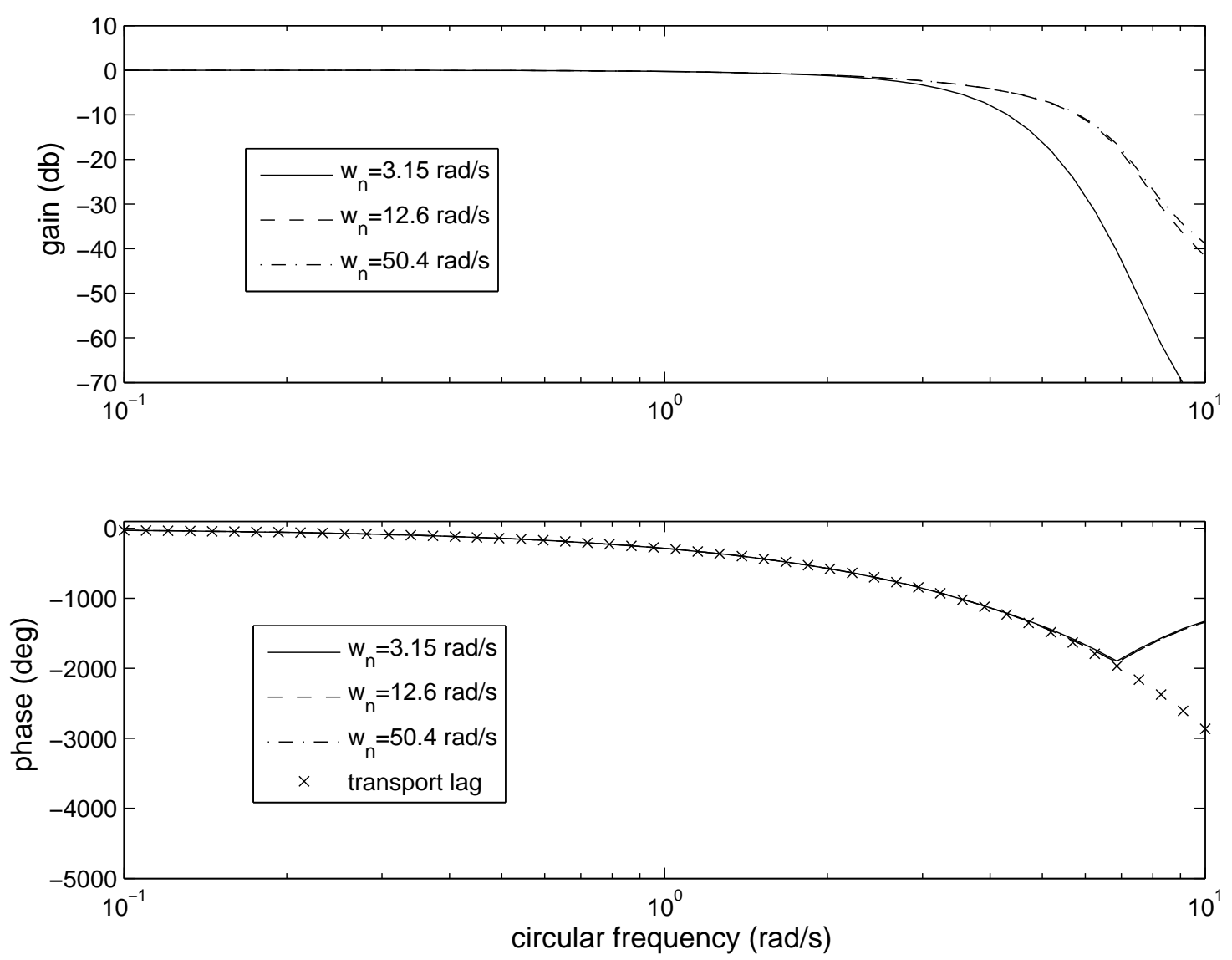

Figure 13: Lateral frequency responses for driver-controlled car linearized around a straight-

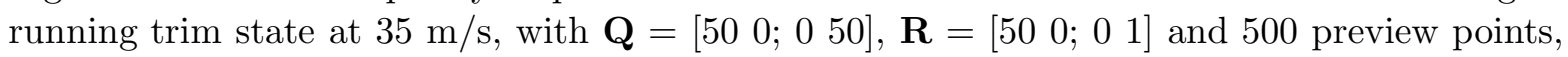
for three driver bandwidths. 
Longitudinally the tracking is perfect for frequencies below $0.4 \mathrm{rad} / \mathrm{s}$ and there are no significant differences between the three systems until the input frequency is $2 \mathrm{rad} / \mathrm{s}$. Then the slowest system attenuates the input more than the others. The system phase lag is the same as the transport lag until the input frequency reaches $2 \mathrm{rad} / \mathrm{s}$. Laterally, the bandwidth is greater, with almost perfect tracking for input frequencies below $1 \mathrm{rad} / \mathrm{s}$. The slowest system is not as good as the other two again beyond about $3 \mathrm{rad} / \mathrm{s}$. As in the longitudinal case, attenuation is a greater problem than phase distortion.

Secondly, the influence of the control tightness on the closed-loop system bandwidth is illustrated by Figures 14 and 15. Here, the conditions are the same as for Figures 12 and 13 except that the driver-filter bandwidth is fixed at $12.6 \mathrm{rad} / \mathrm{s}$ and cases $\mathbf{Q}=\left[\begin{array}{ll}50 & 0 ; 0 \\ 0 & 50\end{array}\right], \mathbf{Q}=$ [500 0; 0 500] or $\mathbf{Q}=[50000 ; 0$ 5000] are treated.
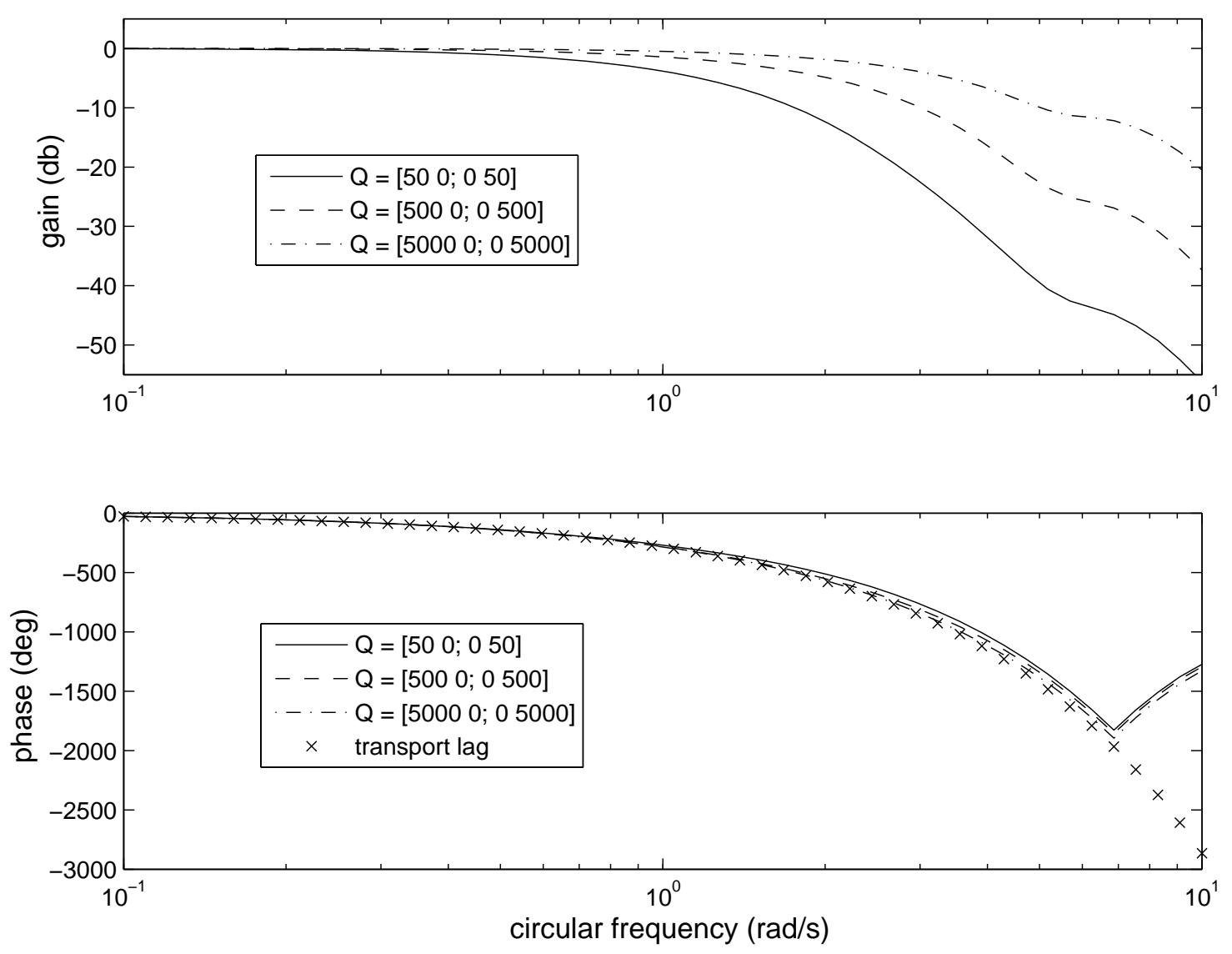

Figure 14: Longitudinal frequency responses for driver-controlled car linearized around a straight-running trim state at $35 \mathrm{~m} / \mathrm{s}$, with filter bandwidth $12.6 \mathrm{rad} / \mathrm{s}, 500$ preview points and $\mathbf{R}=\left[\begin{array}{llll}50 & 0 & 0 & 1\end{array}\right]$, for three levels of control tightness. 

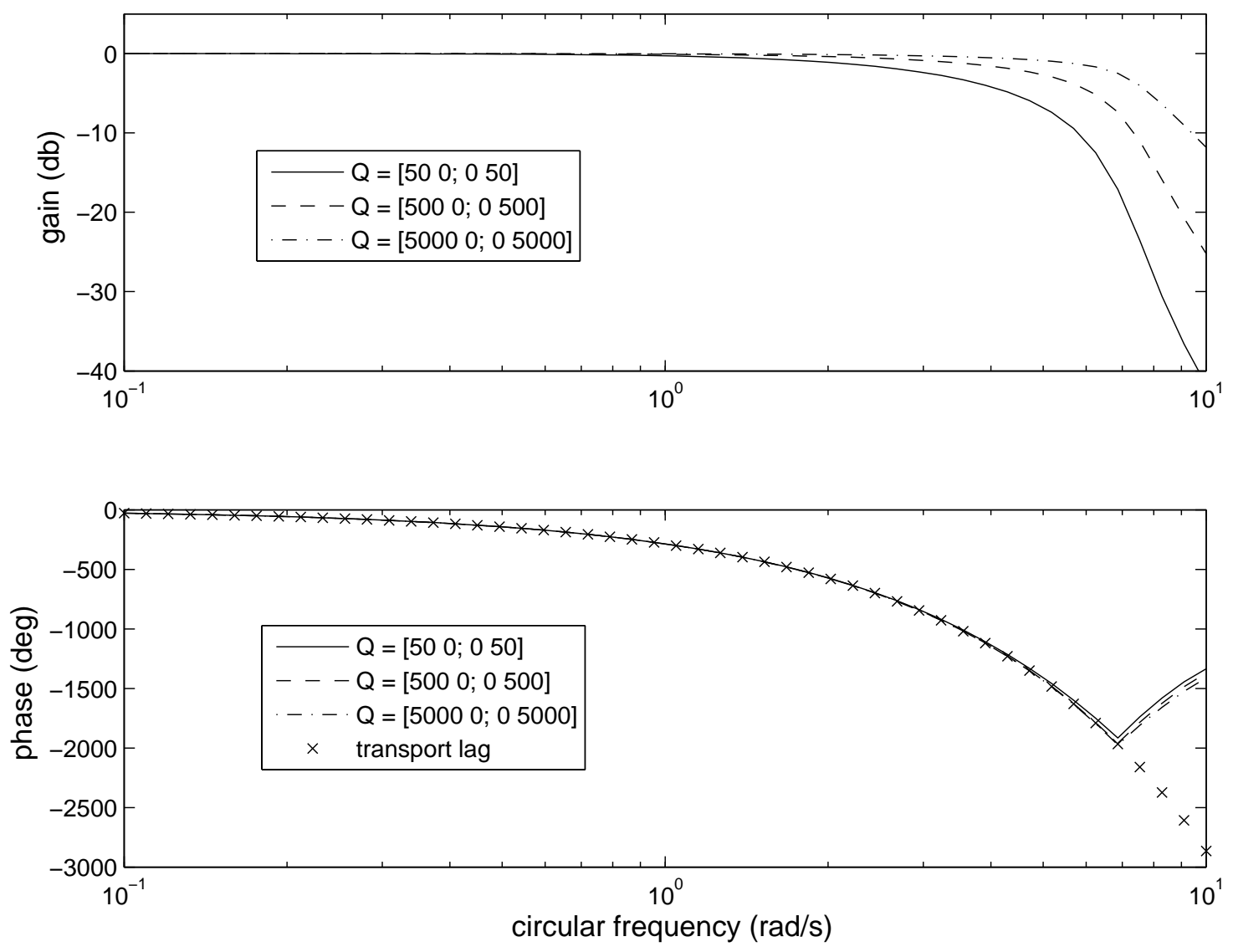

Figure 15: Lateral frequency responses for driver-controlled car linearized around a straightrunning trim state at $35 \mathrm{~m} / \mathrm{s}$, with filter bandwidth $12.6 \mathrm{rad} / \mathrm{s}, 500$ preview points and $\mathbf{R}=$ [50 0; 0 1], for three levels of control tightness. 


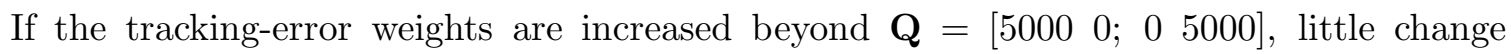
in performance occurs. Tight control will enable perfect tracking longitudinally for circular frequencies below about $1.5 \mathrm{rad} / \mathrm{s}$ and laterally for circular frequencies below about $3 \mathrm{rad} / \mathrm{s}$. For higher frequencies than these, some attenuation will occur, with lesser problems associated with phase distortion.

\section{$5 \quad$ Tracking Simulation Results}

To demonstrate the application of the optimal preview controls, tracking longitudinal and lateral position target sequences by the driver-controlled car are simulated. Each sequence is designed such that the car remains reasonably close to the trim state used in the generation of the controls installed. The chosen trim involves straight-running and is that employed, with $\omega_{n}=12.6 \mathrm{rad} / \mathrm{s}$, to yield the corresponding results of Figures 8 and 9 . Such a trim state implies zero steer angle demand, side-slip and yaw rate, zero out-of-plane displacements and a throttle displacement demand sufficient to maintain the speed against aerodynamic drag. It also implies the car position and attitude angle at intervals of $\mathrm{T}$, the discrete-time interval, over the preview horizon, were the trim controls to be maintained. In a simulation run, the differences between the car states and the trim states are used for feedback control and the distances between the demanded path points and those points implied by the trim state are used for preview control. Both of these controls are added to the trim values to yield the total.

Tracking a generally curved path is only feasible if the controls are transformed from the inertial reference system in which they were established to the local reference system of the car $[25,26,28,30,34]$. The $\mathrm{x}$ - and $\mathrm{y}$-path data points describing the intended trajectory in absolute terms are therefore transformed, at each time step in the simulation, into a driver'sview frame, accounting of course for the current vehicle position. Clearly the transformation has to be done on-line. At each time step, the reference axes for the motion are re-located at the car, which automatically zeros the displacements of the car, $x_{c}, y_{c}$ and $\psi_{c}$, see Figure 6. The loss of the corresponding feedback terms from the controls is exactly compensated by the changes which occur in the preview errors due to the re-positioning of the axes, when full preview is utilised. The control calculation process is illustrated by a snapshot of the car and 
road at a general point along the trajectory in Figure 16.

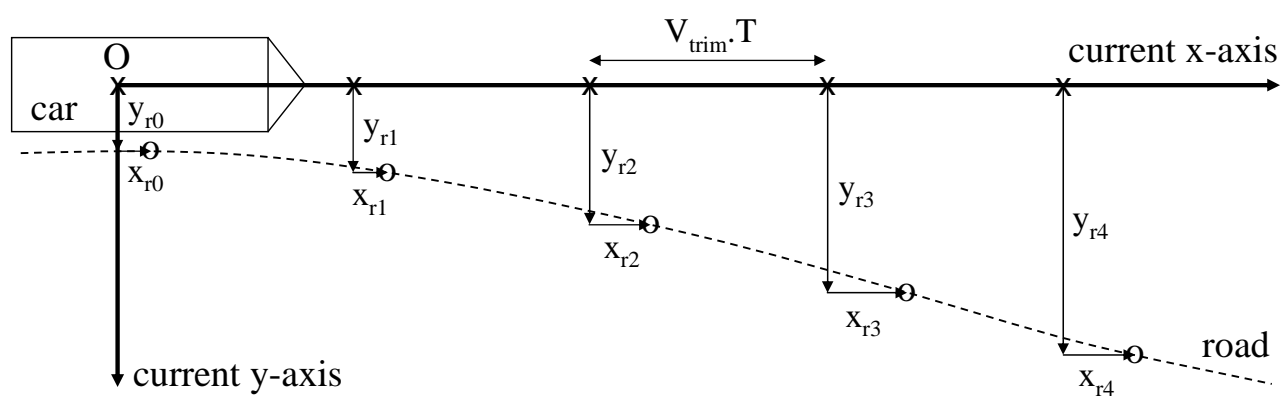

Figure 16: Illustration of control calculations for simulations in which the trim state involves straight running. Points marked ' $x$ ' are the points that the car's reference point would pass through if the trim controls were applied. The points marked 'o' are those specified in the path demand. Both sets of points are for time intervals T. Preview errors used for control calculations are shown as $\left(x_{r i}, y_{r i}\right)$ pairs.

The first tracking test involves a lane change manoeuvre, shown in the first part of Figure 17. The car starts at the origin, parallel to the $\mathrm{x}$-axis, at its trim speed of $35 \mathrm{~m} / \mathrm{s}$. The $\mathrm{x}$-data points describing the road are equi-spaced in time, while the y-data points are obtained by smoothing a ramp/step sequence implying two sharp $5^{\circ}$ direction changes with a fourth-order low-pass Butterworth filter. The speed demand, originally $35 \mathrm{~m} / \mathrm{s}$ throughout the simulation, therefore varies a little near the direction-change stages. The controls installed are those obtained with $\mathbf{Q}=[5000 ; 0500]$ and $\mathbf{R}=[500 ; 01]$ with 500 preview points. Aspects of the simulation results are shown in Figures 18 and 19.

The tracking errors occurring in the lane change manoeuvre are near to zero in the ydirection and reach to $0.0013 \mathrm{~m}$ in the $\mathrm{x}$-direction, with $0.08 \mathrm{rad}$ maximum steering wheel angle being employed, yielding a maximum lateral acceleration less than $1 \mathrm{~m} / \mathrm{s}^{2}$. The throttle opening varies a little around the trim value of 0.1 of full range and the car speed varies from 35 to $35.12 \mathrm{~m} / \mathrm{s}$. The transient response to the initial direction change is not completely over before the second direction change is required, so the later part of the manoeuvre is not just a mirror-image of the first.

In the second test, the car slows from its initial speed in order to traverse a hair-pin bend, see the second part of Figure 17. Then, it speeds up again. The car starts from the origin and initially follows a path parallel to the x-axis at its trim speed of $35 \mathrm{~m} / \mathrm{s}$. After $10 \mathrm{~s}$, while still 

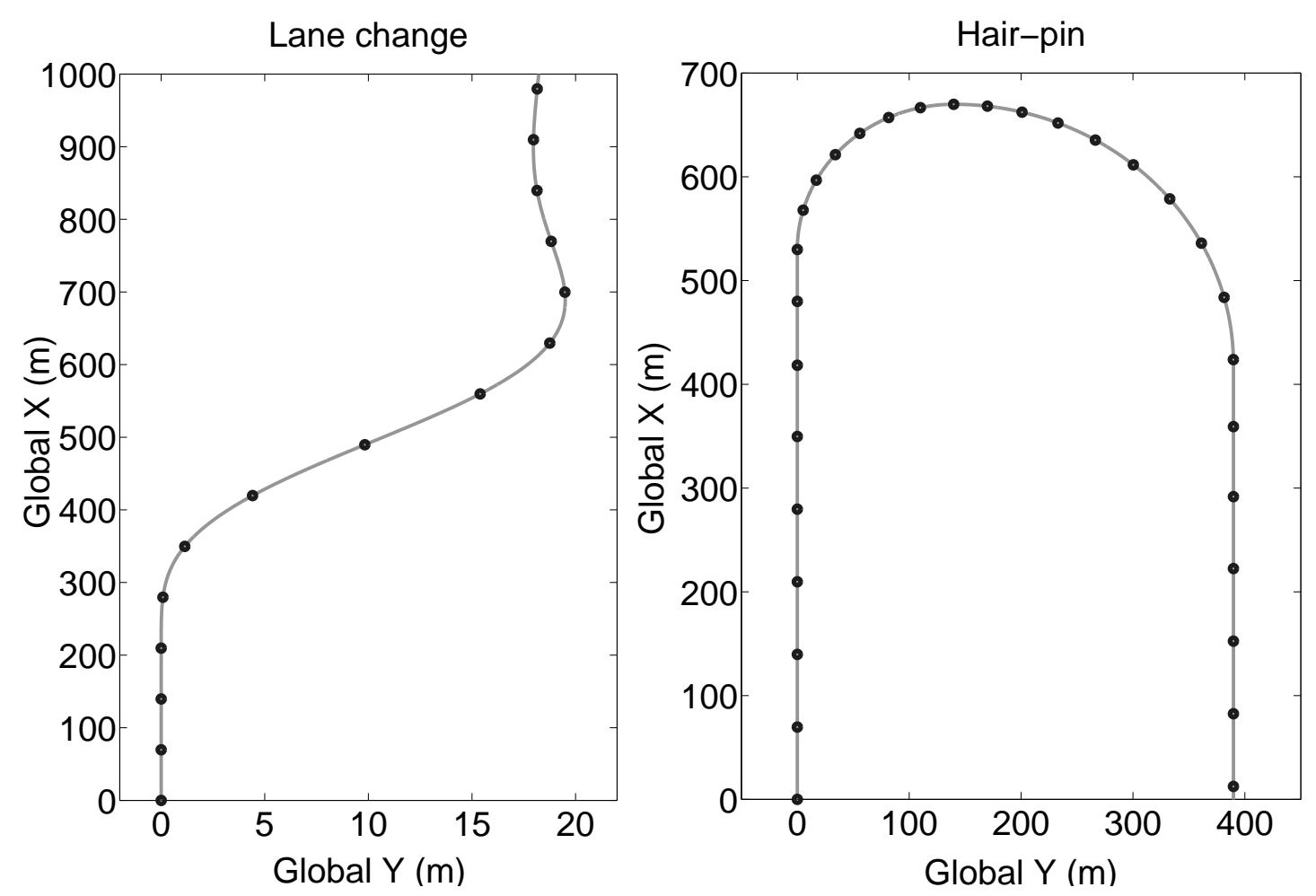

Figure 17: Paths used for tracking tests showing points at $2 \mathrm{~s}$ intervals along them.

travelling in a straight line, the car decelerates to approximately $22 \mathrm{~m} / \mathrm{s}$ in $6 \mathrm{~s}$ until it reaches the corner entry point. It then continues to decelerate for another $4 \mathrm{~s}$ to $15 \mathrm{~m} / \mathrm{s}$ while following the first quadrant of the hair-pin, which has a constant radius of $140 \mathrm{~m}$. The speed is then held constant until the apex of the corner is reached. After the apex, the car accelerates back to its trim speed of $35 \mathrm{~m} / \mathrm{s}$ in $25 \mathrm{~s}$, this time tracking a constant radius of $250 \mathrm{~m}$, eventually exiting the corner and travelling in a straight line. In contrast to the lane change, the path does not contain smooth transition curves which would reduce the need for high-bandwidth system performance. Selected results are shown in Figures 20 - 24.

Tracking errors in the $\mathrm{x}$-direction vary from -0.04 to $0.16 \mathrm{~m}$, while those in the y-direction range over -0.04 to $0.06 \mathrm{~m}$. The steering control range is -0.2 to $0.7 \mathrm{rad}$, while the throttle opening goes from 0 to 0.3 and the brakes are applied for a period of about $10 \mathrm{~s}$. The car body rolls in a somewhat oscillatory fashion with maximum roll angle about $3.5^{\circ}$. The body also pitches significantly with about one half of the roll amplitude, see Figure 22. Tyre loads are shown in Figure 23 and the shear forces developed by the left-front and right-rear tyres 

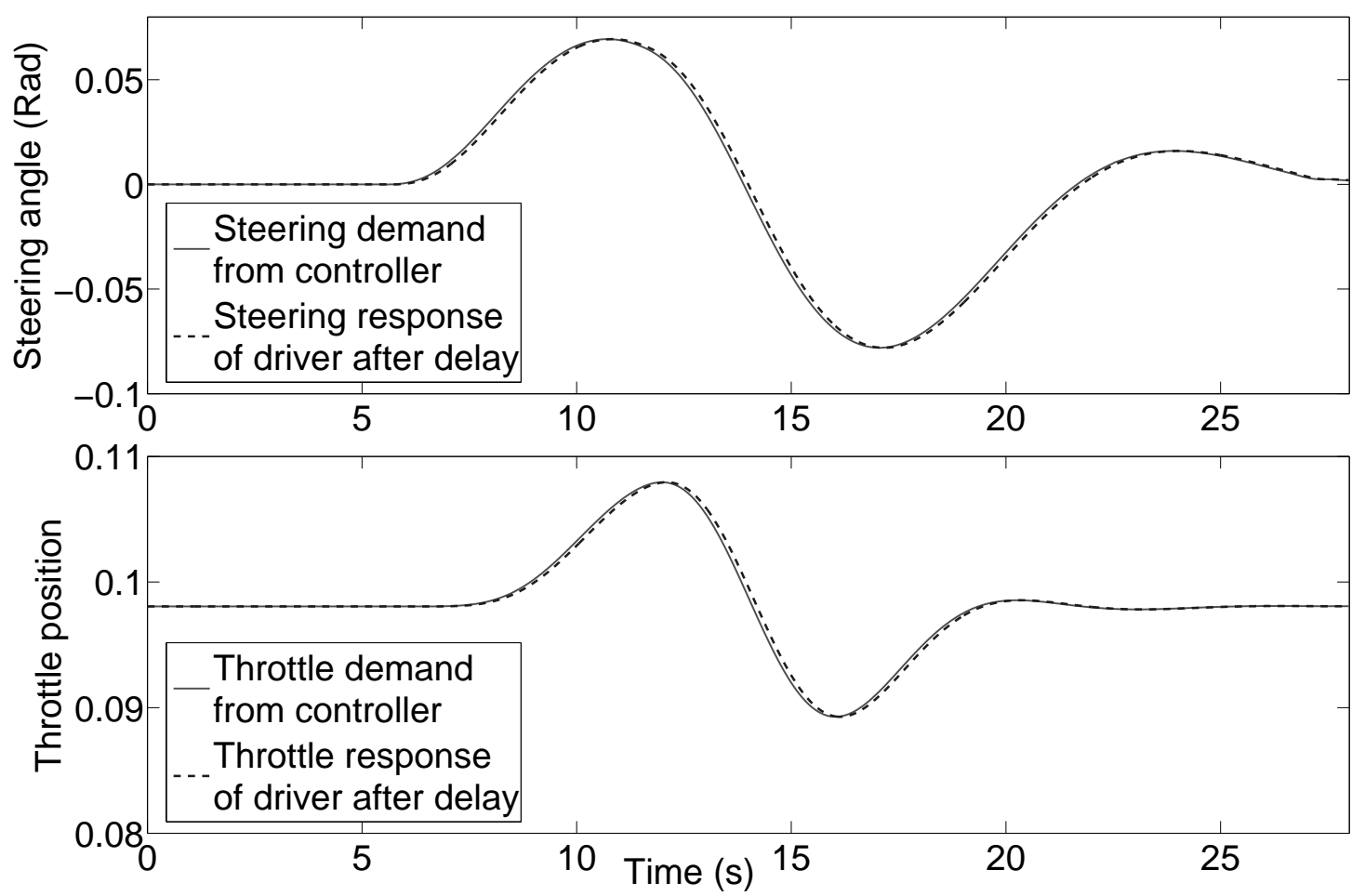

Figure 18: Time histories of steering and throttle controller demands and the delayed driver responses to these demands in tracking the lane change. Note that no braking is necessary in this case.

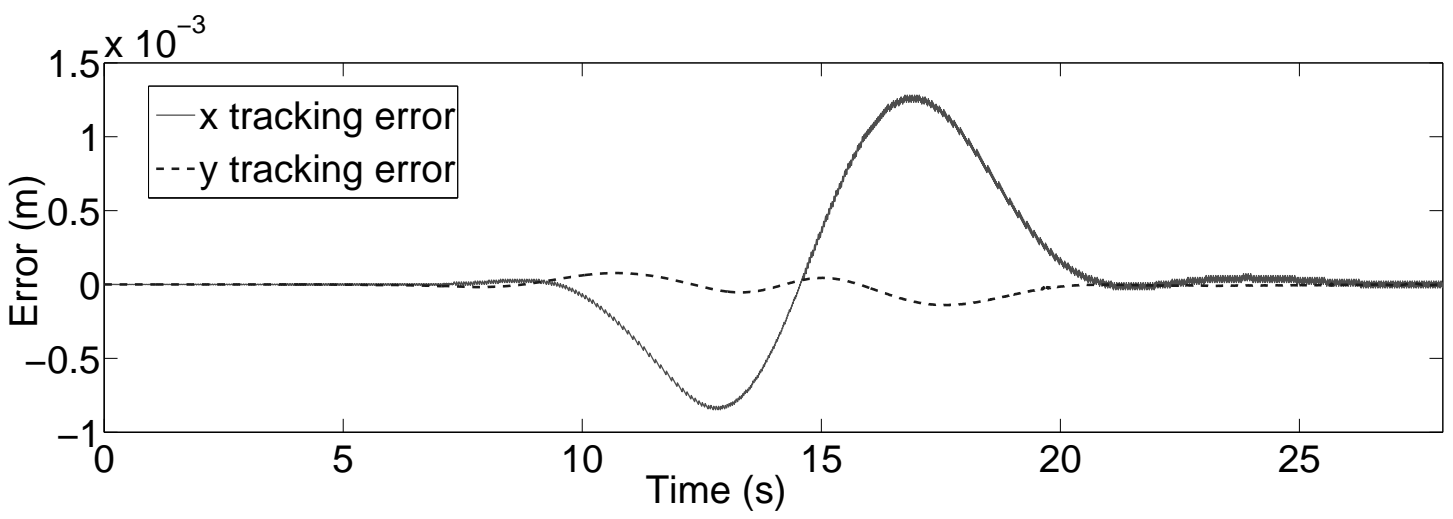

Figure 19: Tracking errors for the lane change, using the same trim state for control design as in Figures 8 and 9 with $\omega_{n}=12.6 \mathrm{rad} / \mathrm{s}$ and $\mathbf{Q}=\left[\begin{array}{lll}500 & 0 ; 0 & 500\end{array}\right]$. 


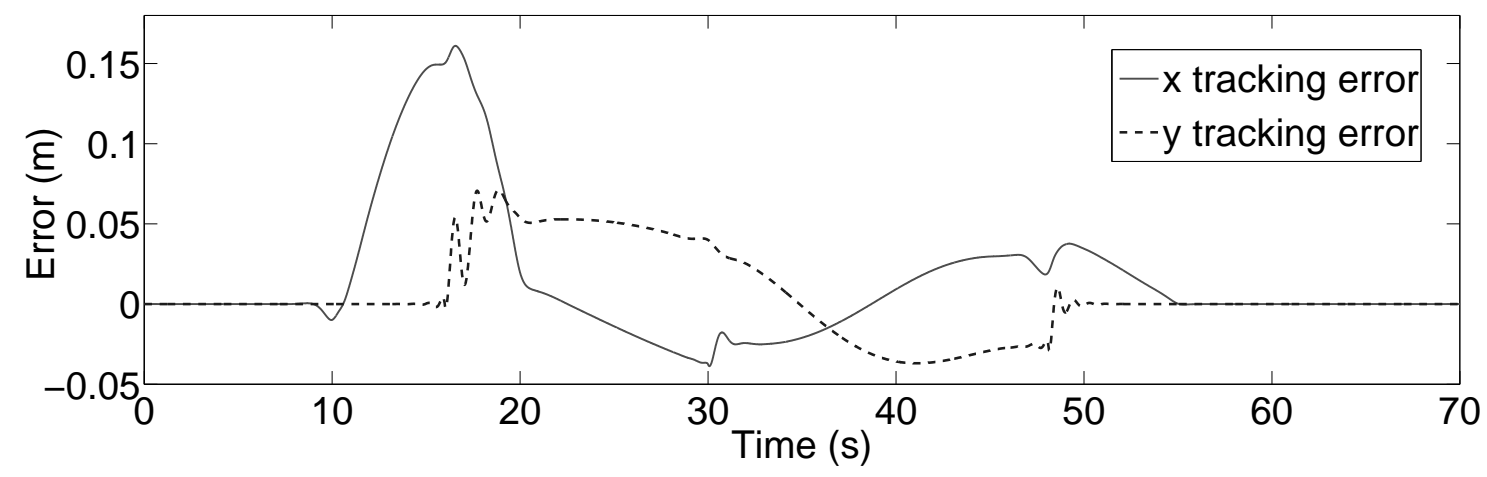

Figure 20: $\mathrm{x}$ - and y-tracking errors for the hair-pin.
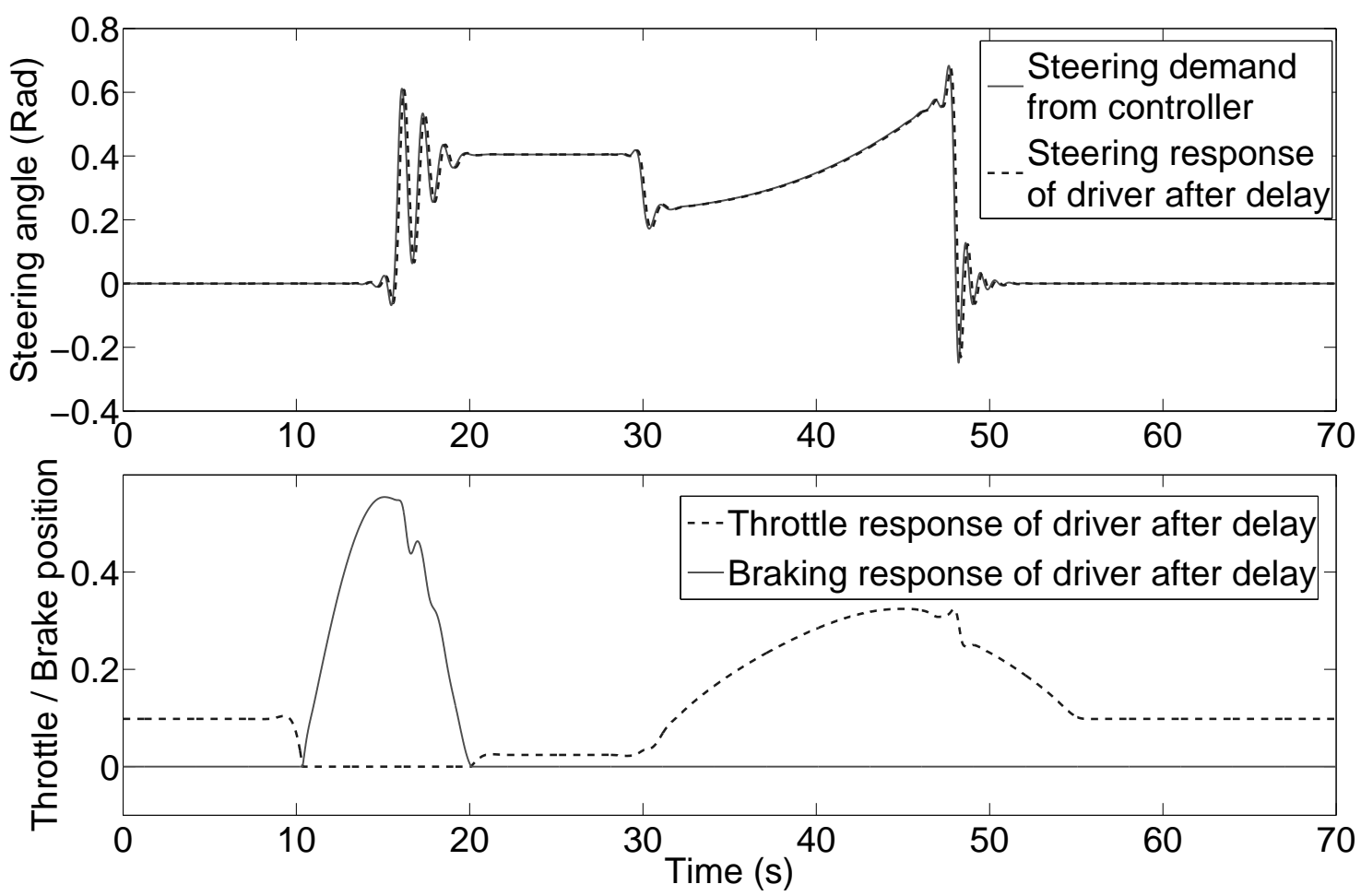

Figure 21: Time histories of steering, throttle and brake controller demands (and the delayed driver responses to these demands) required to track the hair-pin. 

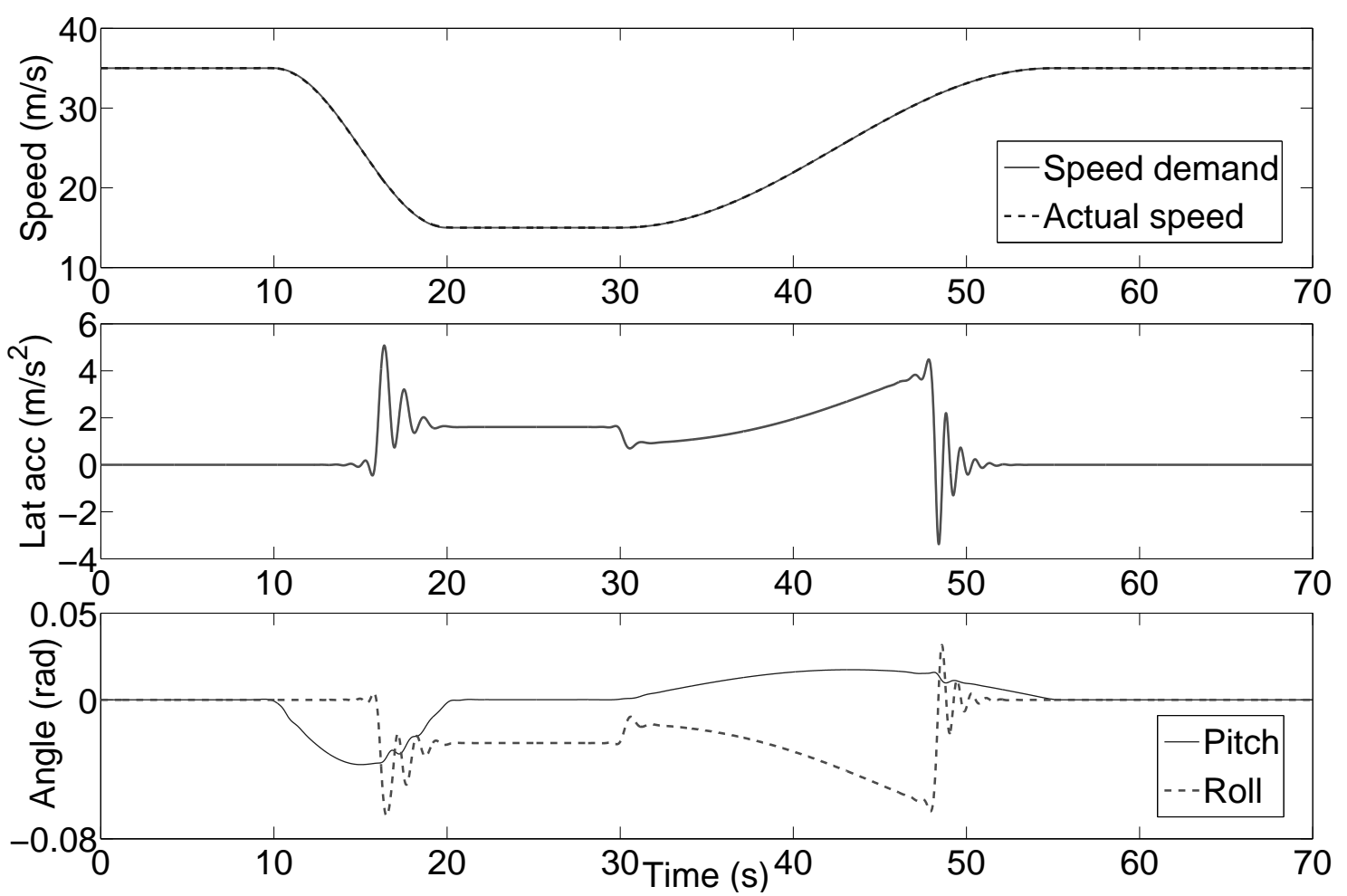

Figure 22: Selected motions for the hair-pin, using the same trim state for control design as in Figures 8 and 9 with $\omega_{n}=12.6 \mathrm{rad} / \mathrm{s}$ and $\mathbf{Q}=\left[\begin{array}{lll}500 & 0 ; 0 & 500\end{array}\right]$. 

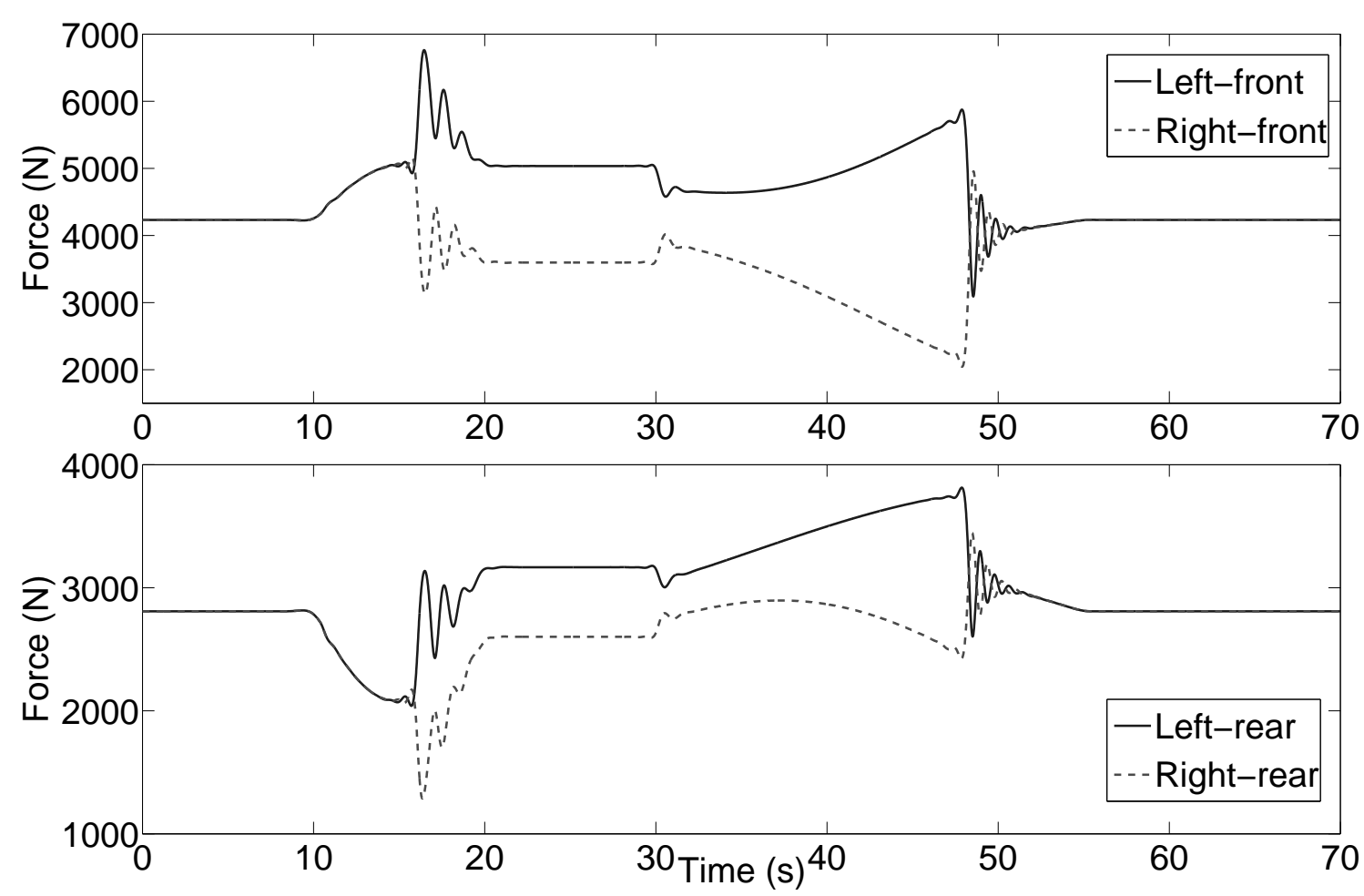

Figure 23: Time histories of tyre loads when tracking the hair-pin.

are plotted in Figure 24. Modest braking forces from the tyres correspond to the brakingcontrol input. The balanced braking system and the free differential gear included in the car's final drive imply that the left-rear tyre longitudinal force is substantially equal to that for the right-rear tyre.

\section{Conclusion}

The work described is motivated by a desire to construct a perfect virtual racing driver, initially, for a flat and level circuit. The strategy used involves the adaptive employment of linear optimal preview controls. Prior research has shown how such controls can be found and applied when only one-dimensional tracking is required. Here, the previous work is extended to the parallel two-dimensional $\mathrm{x}$ - and $\mathrm{y}$-tracking problem for a representative production car with realistic tyre forces. Optimal controls are shown for each of two trim states, one involving straight-running with the left/right symmetry of the problem reflected in the de-coupling of the controls, the other involving cornering, where there is no symmetry and the controls are 

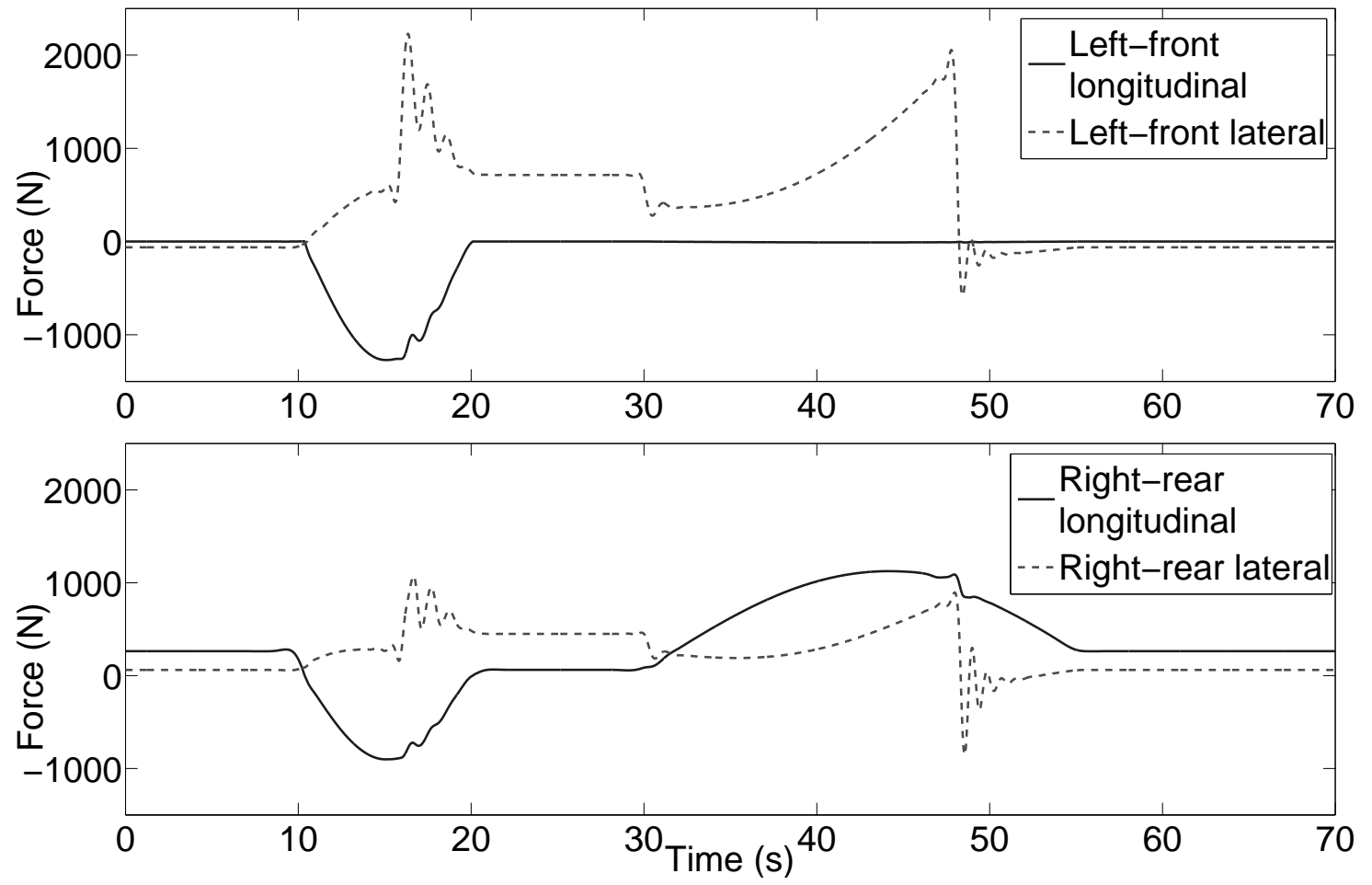

Figure 24: Time histories of left front and right rear tyre shear forces when tracking the hairpin. 
cross-coupled. Throttle and steering actuators are given second-order-lag dynamics to represent driver response-speed limitations and the influence of the bandwidth on the optimal controls is illustrated. Two simulations of combined $\mathrm{x}$ - and $\mathrm{y}$-tracking by a representative optimal driver and car show typical motions and demonstrate the good operation of the closed-loop system. Manoeuvre severity has been deliberately restricted in the cases covered, in recognition of the limitations of linear controls. More severe manoeuvring, with high quality, are possible with adaptive employment of linear optimal preview controls.

\section{Acknowledgment}

The authors are pleased to acknowledge financial support from the UK Engineering and Physical Sciences Research Council and WilliamsF1. We are grateful to Andrew Hazell for making his Toolbox available for use and for advice on using it well.

\section{References}

[1] Anderson, B. D. O. and Moore, J. B.: 1989, Optimal Control: Linear Quadratic Methods, Prentice Hall, Englewood Cliffs, NJ.

[2] Dixon, J. C.: 1996, Tires, Suspension and Handling, 2nd edn, SAE, Warrendale.

[3] Edelmann, J., Plöchl, M., Reinalter, W. and Tieber, W.: 2007, A passenger car driver model for higher lateral accelerations, Vehicle System Dynamics 45(12), 1117-1129.

[4] Findeisen, R. and Allgöwer, F.: 2001, An introduction to nonlinear model predictive control, in C. W. Scherer and J. M. Schumacher (eds), The Impact of Optimisation in Control, Dutch Institute of Systems and Control, pp. 3.1-3.45.

[5] Findeisen, R., Imsland, L., Allgöwer, F. and Foss, B. A.: 2003, State and output feedback nonlinear model predictive control: An overview, European Journal of Control 9(2-3), 179195.

[6] Frezza, R. and Beghi, A.: 2003, Simulating a motorcycle rider, in W. Kang (ed.), New Trends in Nonlinear Dynamics and Control, Springer Verlag, Berlin/Heidelberg. 
[7] Frezza, R. and Beghi, A.: 2006, A virtual motorcycle driver for closed-loop simulation, IEEE Control Syst. Mag. 26(5), 62-77.

[8] Frezza, R., Beghi, A. and Saccon, A.: 2004, Model predictive and hierarchical control for path following with motorcycles: Application to the development of the pilot model for virtual prototyping, Proceedings of 43rd IEEE Conference on Decision and Control, Atlantis, Paradise Island, Bahamas, pp. 767-772.

[9] Frezza, R. and Minen, D.: 2005, A new model based driver program for virtual cars in closed loop simulation, The Dynamics of Vehicles on Roads and on Railway Tracks, Milan, Italy.

[10] Guo, K. and Guan, H.: 1993, Modelling of driver/vehicle directional control system, Vehicle System Dynamics 22(3-4), 141-184.

[11] Hazell, A.: 2008, Discrete-time optimal preview control, PhD thesis, Imperial College London.

[12] Hazell, A. and Limebeer, D. J. N.: 2008, A design framework for discrete-time $\mathcal{H}_{2}$ preview control, Transactions of ASME, Journal of Dynamic Systems, Measurement and Control . in review.

[13] Louam, N., Wilson, D. A. and Sharp, R. S.: 1992, Optimisation and performance enhancement of limited bandwidth active suspensions for automobiles under preview of the road, Vehicle System Dynamics 21(1), 39-63.

[14] MacAdam, C. C.: 2003, Understanding and modelling the human driver, Vehicle System Dynamics 40(1-3), 101-134.

[15] Mousseau, C. W., Sayers, M. W. and Fagan, D. J.: 1992, Symbolic quasi-static and dynamic analyses of complex automobile models, in G. Sauvage (ed.), Proc. $12^{\text {th }}$ IAVSD Symposium on the Dynamics of Vehicles on Roads and on Tracks, Swets and Zeitlinger, Lisse, pp. 446-459.

[16] Pacejka, H. B.: 2002, Tyre and Vehicle Dynamics, Butterworth Heinemann, Oxford. ISBN 0-7506-5141-5. 
[17] Plöchl, M. and Edelmann, J.: 2007, Driver models in automobile dynamics application, Vehicle System Dynamics 45(7-8), 699-741.

[18] Prokop, G.: 2001, Modelling human vehicle driving by model predictive on-line optimisation, Vehicle System Dynamics 35(1), 19-35.

[19] Prokop, G. and Sharp, R. S.: 1995, Performance enhancement of limited bandwidth active automotive suspensions by road preview, IEE Proc. Control Theory and Applications 142(2), 140-148.

[20] Qin, S. J. and Badgwell, T. A.: 2003, A survey of industrial model predictive control technology, Control Engineering Practice 11(7), 733-764.

[21] Rawlings, J. B.: 2000, Tutorial overview of model predictive control, IEEE Control Syst. Mag. pp. $38-52$.

[22] Sayers, M. W.: 1999, Vehicle models for rts applications, Vehicle System Dynamics 32(45), 421-438.

[23] Schiehlen, W. O.: 1997, Multibody system dynamics: Roots and perspectives, Multibody System Dynamics 1(2), 149-188.

[24] Sharp, R. S.: 2004, Testing and improving a tyre shear force computation algorithm, Vehicle System Dynamics 41(3), 223-247.

[25] Sharp, R. S.: 2005, Driver steering control and a new perspective on car handling qualities, Journal of Mechanical Engineering Science 219(C8), 1041-1051.

[26] Sharp, R. S.: 2006, Optimal linear time-invariant preview steering control for motorcycles, in S. Bruni and G. R. M. Mastinu (eds), The Dynamics of Vehicles on Roads and on Railway Tracks, Taylor and Francis, London, pp. 329-340. Supplement to Vehicle System Dynamics, Vol. 44.

[27] Sharp, R. S.: 2007a, Application of optimal preview control to speed tracking of road vehicles, Journal of Mechanical Engineering Science 221(12), 1571-1578. 
[28] Sharp, R. S.: 2007b, Motorcycle steering control by road preview, Transactions of ASME, Journal of Dynamic Systems, Measurement and Control 129(4), 373-381.

[29] Sharp, R. S.: 2007c, Optimal preview speed-tracking control for motorcycles, Multibody System Dynamics 18(3), 397-411.

[30] Sharp, R. S.: 2007d, Optimal stabilisation and path-following controls for a bicycle, Journal of Mechanical Engineering Science 221(4), 415-428.

[31] Sharp, R. S. and Bettella, M.: 2003a, On the construction of a general numerical tyre shear force model from limited data, Proc. I. Mech. E. Part D, Journal of Automobile Engineering 217(3), 165-172.

[32] Sharp, R. S. and Bettella, M.: 2003b, Tyre shear force and moment descriptions by normalisation of parameters and the "magic formula", Vehicle System Dynamics 39(1), 27-56.

[33] Sharp, R. S., Evangelou, S. and Limebeer, D. J. N.: 2005, Multibody aspects of motorcycle modelling with special reference to autosim, in J. A. C. Ambrosio (ed.), Advances in Computational Multibody Systems, Springer-Verlag, Dordrecht, The Netherlands, pp. 4568.

[34] Sharp, R. S. and Valtetsiotis, V.: 2001, Optimal preview car steering control, in P. Lugner and K. Hedrick (eds), ICTAM Selected Papers from 20th International Congress, Swets and Zeitlinger, Lisse, pp. 101-117. Supplement to Vehicle System Dynamics Vol. 35.

[35] Thommyppillai, M., Evangelou, S. and Sharp, R. S.: 2009a, Car driving at the limit by adaptive linear optimal preview control, Vehicle System Dynamics in press.

[36] Thommyppillai, M., Evangelou, S. and Sharp, R. S.: 2009b, Rear-heavy car control by adaptive linear optimal preview, Vehicle System Dynamics in press.

[37] Ungoren, A. Y. and Peng, H.: 2005, An adaptive lateral preview driver model, Vehicle System Dynamics 43(4), 245-259. 